\title{
AVALIAÇÃO DAS ACESSIBILIDADES NAS ESCOLAS MUNICIPAIS DA CIDADE DE JUIZ DE FORA
}

\section{ARTIGO ORIGINAL}

FÁVERO, Cristina Hill ${ }^{1}$

FÁVERO, Cristina Hill. Avaliação das acessibilidades nas escolas municipais da

Cidade de Juiz de Fora. Revista Científica Multidisciplinar Núcleo do Conhecimento. Ano 05, Ed. 11, Vol. 07, pp. 141-171. Novembro de 2020. ISSN: 2448-0959, Link de acesso:https://www.nucleodoconhecimento.com.br/educacao/juiz-de-fora

\section{RESUMO}

$\mathrm{Na}$ literatura atual acessibilidade se traduz como a redução de barreiras que impedem as pessoas com deficiências de exercerem plenamente seus direitos como cidadãos. Um direito fundamental do cidadão é educação de qualidade e para que esta aconteça com qualidade e eficácia, a acessibilidade é peça motriz do processo de inclusão educacional. Neste contexto, surge a seguinte questão, como avaliar a acessibilidade às escolas? $\mathrm{O}$ objetivo deste estudo é descrever um modelagem proposta para a avaliação deste tipo de acessibilidade. Os critérios de avaliação aplicados na modelagem são oriundos de pesquisa bibliográfica sistematizada, o que originou um instrumento de avaliação composto por 47 critérios, agrupados nas dimensões de acessibilidade arquitetônica, metodológica, comunicacional, instrumental, atitudinal e programática. Esse instrumento de coleta foi aplicado a um caso específico, que teve com pano de fundo a avaliação da acessibilidade nas escolas municipais da cidade de Juiz de Fora, situada no Estado de Minas Gerais, na região Sudeste do Brasil. O preenchimento do modelo de pesquisa se deu por meio de e-mails, visitas as escolas

\footnotetext{
${ }^{1}$ Mestrado em Sistema de Gestão - UFF; MBA em Organização e Estrátégias - UFF; Pós-Graduada de Educação Especial - UNIRIO e LIBRAS - Dom Alberto; Graduada em Pedagogia - UFJF; Graduanda em Letras-Libras - UFJF e Letras/Português Pitágoras/UNOPAR
} 
municipais e entrevistas em encontros individuais. Identificou-se insuficiência de acessibilidade arquitetônica e comunicacional, ficando os critérios piso tátil e utilização de braile em sala, pertencentes as acessibilidades com os percentuais abaixo de $10 \%$ do total possível. Dentre as acessibilidades avaliadas, os critérios relacionados a atitudinal e programática predominaram as porcentagens mais altas. O conhecimento das condições de acessibilidade permitiu aos pesquisadores proporem ações pertinentes a construção ou melhorias de acessibilidades.

Palavras Chave: Acessibilidade, avaliação, deficiência, inclusão.

\section{INTRODUÇÃO}

No decorrer dos anos a sociedade vem alcançando avanços significativos no que se refere a inclusão social e educacional dos indivíduos com deficiência. Todas as mudanças ocorridas, desde os início da civilização até os dias atuais, se tornaram possível devido jornada exaustiva de lutas e organizações de grupos sociais deficientes, negros, homossexuais, mulheres e outros - notoriamente marcados por abandono, exclusão e preconceito no meio acadêmico e social.

No processo de inclusão, a implantação da acessibilidade é uma das tarefas mais árduas a ser realizada, visto que a sociedade ainda é despreparada para atender com eficiência e eficácia as necessidades da diversidade dos indivíduos nela inseridos.

Mesmo com avanços históricos e conquistas atuais como os primeiros movimentos pelos direitos dos indivíduos com deficiências, o surgimento da preocupação em se eliminar barreiras arquitetônicas e a evolução do conceito de acessibilidade abrangendo outras vias que não somente as estruturas edificadas, bem como ao direito de inclusão à cidadania, há ainda muito que ser conquistado.

Atualmente ainda nos deparamos com espaços públicos sem qualquer modificação e/ou adaptações necessárias para atender aos cidadãos que os utiliza. Segundo Audi e Manzini (2007), a escola é exemplo material da falta de acessibilidade e a solução encontra-se distante. Observa-se que as estruturas físicas das instituições escolares 
são péssimas e em muitas das vezes os profissionais que nela atuam demonstram despreparo para lidar com especificidades peculiares aos indivíduos com deficiência.

Deste modo, avaliar a promoção das acessibilidades e para futuro planejamento da educação inclusiva e implantações de acessibilidades torna-se imprescindível para que os direitos destes indivíduos sejam resguardados e que não continuem sendo excluídos social e educacionalmente.

\section{BASE CONCEITUAL}

Acessibilidade é um termo que não se pode definir com conceito único, seu significado abrange diversos sentidos, pode ser empregado nos mais variados contextos e utilizada por todos os indivíduos de uma sociedade. Presente na Associação Brasileira de Normas Técnicas (ABNT, 2004), acessibilidade é descrita como "a possibilidade e condição de alcance, percepção e entendimento para a utilização com segurança e autonomia de edificações, espaço, mobiliário, equipamento urbano e elementos".

No processo de transformação de uma realidade excludente em uma nova vivência inclusiva, a acessibilidade é peça motriz e indissociável do processo. A modificação da realidade existente e a construção de ambientes acessíveis devem ser prioridade dos gestores e de todos os sujeitos que acreditam na mudança como única forma progresso social. (PUPO, 2006)

As mudanças ao atingirem o ambiente educacional, durante a fase inicial de transformação, é necessária a realização de sensibilização da comunidade escolar e de seu entorno que opta por conhecer um pouco mais sobre inclusão e acessibilidade. Nesta fase é primordial o estudo sobre acessibilidade e seus conceitos para que todos possam aderir conscientemente à proposta da inclusão.

Diferentes legislações e autores procuram definir acessibilidade ou adequar o termo as necessidades dos indivíduos. Busca-se, efetivamente, através de modificações e adaptações diminuir as barreiras diversas que distanciam os indivíduos de uma vida autônoma e de qualidade. 
No ano de 2000, na lei $n^{\circ} 10.098$ a acessibilidade é descrita como a "possibilidade e condição de alcance para utilização, com segurança e autonomia, dos espaços, mobiliários e equipamentos urbanos, das edificações, dos transportes e dos sistemas e meios de comunicação, por pessoa portadora de deficiência ou com mobilidade reduzida". É uma lei restrita, pois aborda componentes relacionados somente às acessibilidades arquitetônica e comunicacional.

O decreto no 5.296/04 amplia o termo acessibilidade quando adota a inclui as tecnologias no seu escopo. O decreto define acessibilidade como:

[...] condição para utilização, com segurança e autonomia, total ou assistida, dos espaços, mobiliários e equipamentos urbanos, das edificações, dos serviços de transporte e dos dispositivos, sistemas e meios de comunicação e informação, por pessoa portadora de deficiência ou com mobilidade reduzida. (BRASIL, 2004)

A Convenção da Organização das Nações Unidas (ONU) Sobre os Direitos das Pessoas com Deficiência (2006) trata a acessibilidades de forma mais ampla ao abranger todos os aspectos da vida. Assim, assegura a acessibilidade como direito e diz:

A fim de possibilitar às pessoas com deficiência viver de forma independente e participar plenamente de todos os aspectos da vida, os Estados Partes tomarão as medidas apropriadas para assegurar às pessoas com deficiência o acesso, em igualdade de oportunidades com as demais pessoas, ao meio físico, ao transporte, à informação e comunicação, inclusive aos sistemas e tecnologias da informação e comunicação, bem como a outros serviços e instalações abertos ao público ou de uso público, tanto na zona urbana como na rural. Convenção da Organização das Nações Unidas (ONU) Sobre os Direitos das Pessoas com Deficiência (13/12/2006) (ONU, 2006)

Para Sassaki (2005), o termo acessibilidade é atual, nascendo na década de 40, a partir do aparecimento dos serviços da reabilitação física e profissional, aos poucos se estendendo pela sociedade nos idos de 50, atingindo o meio acadêmico americano na década de 60, na década de 70 amplia a preocupação com as barreiras arquitetônicas, em 80 a preocupação se estende não só eliminar as barreiras, 
mas também a não inseri-las nos projetos arquitetônicos e na década de 90 surge o paradigma do desenho universal.

conceito de acessibilidade pode ser analisado nos mais variados contextos e dividido em seis dimensões: arquitetônica, comunicacional, metodológica, instrumental, programática e atitudinal. Sassaki (2005) considerada todas as dimensões como importantes, complementares e indispensáveis para o processo de inclusão efetivo e de qualidade. Dessa maneira dentro do ambiente educacional, as dimensões proposta são detalhadas da seguinte forma:

- Acessibilidade arquitetônica: eliminação das barreiras físicas que dificultam o acesso aos ambientais. O acesso e adaptações físicas dos espaços, desde a entrada até as salas, bem como em toda a área de circulação deve ser assegurado.

- Acessibilidade comunicacional: eliminação das barreiras de comunicação interpessoal e escrita. A utilização de recursos diversos, línguas e linguagens que venham a facilitar a comunicação, devem ser assegurados no processo educacional;

- Acessibilidade metodológica: eliminação das barreiras nos métodos pedagógicos e técnicas de estudos. A compreensão da Teoria das Inteligências Múltiplas, por parte da comunidade escolar, pode ser fator sine qua non do sucesso do processo de ensino aprendizagem;

- Acessibilidade instrumental: eliminação das barreiras nos instrumentos, utensílios e ferramentas pedagógicas. A adaptação de materiais de forma que todos os indivíduos poderão utilizá-los nos momentos de aprendizagem;

- Acessibilidade programática: eliminação das barreiras ocultas em políticas públicas (leis, decretos, portarias e resoluções) que possam impedir ou dificultar a participação plena de todos os indivíduos, com ou sem deficiência, na vida escolar;

- Acessibilidade atitudinal: eliminação de atitudes preconceituosas, estigmatizantes, estereotipadas e discriminatórias. A promoção de atividades 
na escola e seu entorno promovem a sensibilização, conscientização e estimulam a convivência dos indivíduos participes do processo educacional.

Mesmo com essa ampla definição de acessibilidades, Roberto Kazumi Sassaki, (2005) trabalha com as tecnologias (assistivas, digitais, de informação e comunicação), não como mais uma dimensão, e sim como tema que permeia as cinco dimensões supracitadas. As contribuições das tecnologias para a melhoria da qualidade da educação dos indivíduos deficientes são indiscutíveis.

A análise de alguns documentos, legislações e autores apresentam-se como fonte de entendimento sobre de que modo a acessibilidade vem sendo tratada no decorrer dos anos pelos gestores públicos e pesquisadores e aponta que todos os elaboradores dos documentos, leis e artigos coincidem em identificar as necessidades físicas e intelectuais dos indivíduos deficientes como fatores chave na promoção da acessibilidade. (CAMARGO, 2010)

\section{METODOLOGIA}

O modelo de pesquisa utilizado para avaliar as acessibilidades promovidas pela educação municipal da cidade de Juiz de Fora foi construído pelos pesquisadores, após estudo dos artigos pesquisados nas bases SciELO e SCOPUS, através do acesso ao Portal de periódicos da CAPES período de abril e julho de 2013. Durante o estudo dos artigos, buscou-se levantar itens relacionados as acessibilidades e adaptalos ao ambiente escolar, sem esquecer as especificidades de cada variável. Desse modo, o novo modelo de avaliação enfoca essencialmente os aspectos referentes as 6 acessibilidades: arquitetônica, metodológica, comunicacional, instrumental, atitudinal e programática

Inicialmente um modelo foi construído e testado por cinco educadores durante avaliação da acessibilidade na escola em que trabalhavam, estes apontaram algumas falhas relacionadas a ausência de informações em relação as notas e dúvidas referentes as questões a serem respondidas e sugeriram alterações e acréscimos. Observadas as dificuldades, os pesquisadores fizeram as alterações sugeridas. 
O modelo final compõe-se de um roteiro com 47 questões organizadas de acordo as variáveis pertencentes a cada acessibilidade. Assim o modelo de avaliação aborda questões arquitetônicas (ampliação de corredores, rampas, adaptações de banheiros), metodológicas (formação profissional, modalidades de ensino), instrumental (computadores, data show), comunicacional (comunicação alternativa, braile, Libras), atitudinal (relacionamentos interpessoais) e programáticas (legislações, sistema político). O modelo também contém espaço para outras informações: cargo ocupado pelo respondente e as deficiências atendidas pela escola.

O modelo de avaliação da acessibilidade foi utilizado para avaliar as escolas municipais de Juiz de Fora, que perfazem um total de 102 escolas distribuídas por todo o município e atendem a alunos com deficiências incluídos em salas de aulas do ensino regular. Com o consentimento da Secretaria de Educação os gestores das instituições foram convidados a participar da pesquisa, sendo o contato feito através de email, telefonemas e posteriores visitas as escolas.

Aplicados os modelos de avaliação, os pesquisadores passaram para análise dos dados obtidos. Para organização dos dados optou-se pela criação de 6 tabelas distintas, referentes a cada acessibilidade e suas variáveis. Para a construção das tabelas, utilizou-se o programa Excel na computação dos dados e durante o processo de digitação item por item dos modelos preenchidos pelos participes da pesquisa foram averiguados. Durante 0 processo de pesquisa das acessibilidades, paralelamente, aconteceram as entrevistas com três gestores da Secretaria de Educação.

\section{RESULTADOS}

Todas as escolas foram convidadas a participar da pesquisa e o universo da amostra ficou distribuído em: $68 \%$ do total da amostra responderam à pesquisa, 20\% não responderam à pesquisa e 12\% escolas não responderam por dizerem não se incluir na realidade pesquisada. Para melhor visualização os dados foram explanados no gráfico 1: 
Gráfico 1 - Distribuição do universo da amostra por respostas

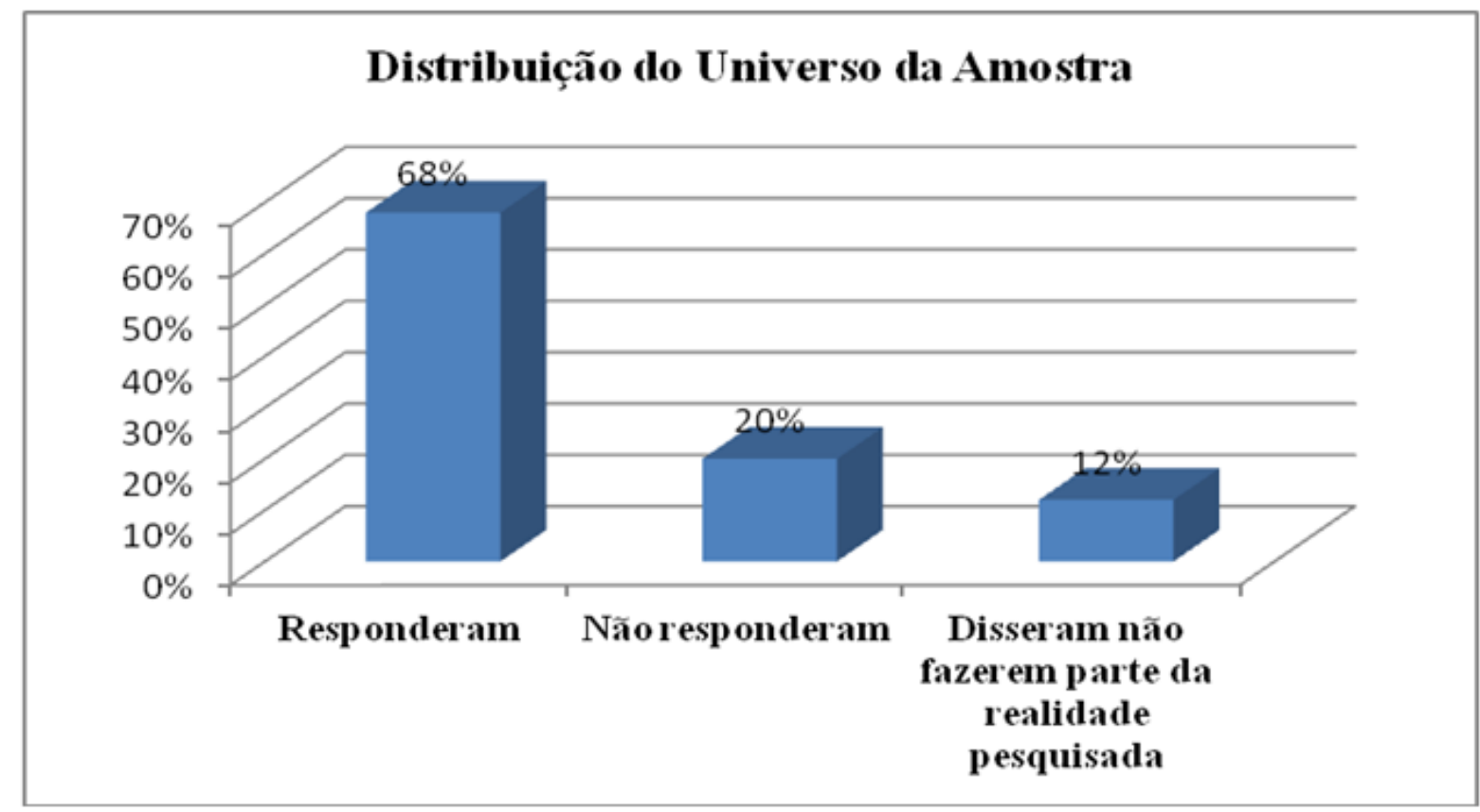

Fonte: Elaborado pela pesquisadora

As escolas avaliadas atendem a alunos com deficiências diversas. Identificou-se que escolas atendem a mais de uma deficiência, contudo é o menor número de escolas atendendo as deficiências auditivas e visuais, como mostra o gráfico 2.

Gráfico 2 - Distribuição de frequência de deficiências por escolas 


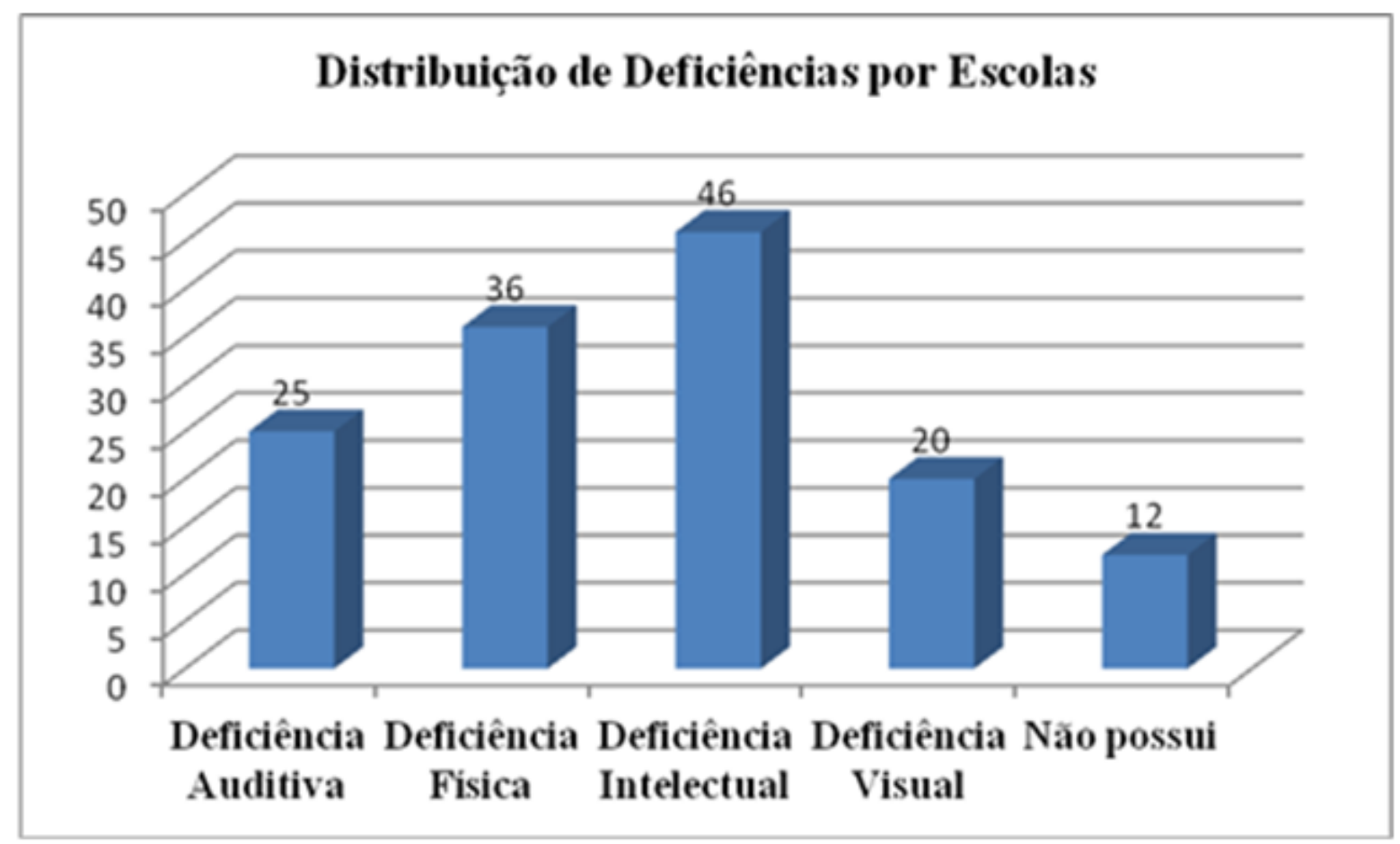

Fonte: Elaborado pela pesquisadora

As tabelas foram formuladas com dados da pesquisa obtidos do instrumento de coleta e separadas nas dimensões: arquitetônica, metodológica, instrumental, comunicacional, atitudinal e programática. As variáveis de cada dimensão receberam codificações e as pontuações recebidas somadas, transformadas em percentuais para melhor análise separadas por cor, destacando em branco as variáveis com pontuação superior a $50 \%$. A seguir estão expostas as tabelas.

- ACESSIBILIDADE ARQUITETÔNICA: analisadas as divisões das variáveis: ampliação da largura dos corredores (A1), ampliação da área de circulação nas salas (A2), rampa para a entrada (A3), rampa para as salas (A4), rampa para o banheiro (A5), rampa para a biblioteca (A6), sanitários adaptados (A7), barras de apoio (A8), piso antiderrapante (A9), piso tátil (A10) e desníveis (A11).

Tabela 1 - Pontuações das escolas nas subdivisões das variáveis da Acessibilidade Arquitetônica 


\begin{tabular}{|c|c|c|c|c|c|c|c|c|c|c|c|c|c|}
\hline \multicolumn{10}{|c|}{ DIMENSÃO: ACESSIBIIDADE ARQUITETÔNICA } \\
\hline ESCOLAS & A1 & A2 & A3 & A4 & A5 & A6 & A7 & A8 & A9 & A10 & A11 & $\begin{array}{c}\text { Pontos } \\
\text { total }\end{array}$ & $\begin{array}{c}\% \text { da } \\
\text { Pontuação } \\
\text { possivel }\end{array}$ \\
\hline 1. & 5 & 0 & 10 & 10 & 10 & 0 & 10 & 0 & 0 & 0 & 3 & 48 & $44 \%$ \\
\hline 2. & 10 & 0 & 0 & 0 & 0 & 10 & 0 & 0 & 0 & 0 & 10 & 30 & $27 \%$ \\
\hline 3. & 5 & 2 & 7 & 7 & 7 & 7 & 8 & 8 & 7 & 2 & 5 & 65 & $59 \%$ \\
\hline 4. & 2 & 2 & 9 & 9 & 9 & 8 & 7 & 2 & 2 & 0 & 0 & 50 & $45 \%$ \\
\hline 5. & 10 & 5 & 10 & 10 & 10 & 10 & 10 & 10 & 0 & 0 & 0 & 75 & $68 \%$ \\
\hline 6. & 5 & 5 & 6 & 5 & 6 & 0 & 10 & 5 & 3 & 2 & 0 & 47 & $43 \%$ \\
\hline 7. & 0 & 0 & 0 & 0 & 0 & 0 & 0 & 0 & 0 & 0 & 0 & 0 & $0 \%$ \\
\hline 8. & 0 & 0 & 0 & 0 & 0 & 0 & 10 & 0 & 0 & 0 & 0 & 10 & $9 \%$ \\
\hline 9. & 3 & 3 & 0 & 2 & 1 & 1 & 0 & 6 & 1 & 1 & 1 & 19 & $17 \%$ \\
\hline 10. & 5 & 5 & 0 & 0 & 0 & 0 & 0 & 0 & 5 & 0 & 0 & 15 & $14 \%$ \\
\hline 11. & 7 & 7 & 8 & 7 & 8 & 9 & 5 & 6 & 3 & 5 & 4 & 69 & $63 \%$ \\
\hline 12. & 5 & 1 & 6 & 0 & 0 & 7 & 0 & 0 & 0 & 0 & 0 & 19 & $17 \%$ \\
\hline 13. & 2 & 0 & 7 & 0 & 0 & 0 & 0 & 0 & 0 & 0 & 0 & 9 & $8 \%$ \\
\hline 14. & 0 & 0 & 0 & 0 & 0 & 0 & 0 & 3 & 0 & 0 & 0 & 3 & $3 \%$ \\
\hline 15. & 10 & 8 & 0 & 0 & 0 & 0 & 10 & 5 & 8 & 0 & 1 & 42 & $38 \%$ \\
\hline 16. & 9 & 2 & 0 & 0 & 4 & 4 & 9 & 9 & 6 & 0 & 0 & 43 & $39 \%$ \\
\hline 17. & 10 & 5 & 0 & 0 & 5 & 0 & 2 & 0 & 0 & 0 & 0 & 22 & $20 \%$ \\
\hline 18. & 2 & 2 & 0 & 0 & 0 & 0 & 0 & 0 & 0 & 0 & 0 & 4 & $4 \%$ \\
\hline 19. & 5 & 5 & 0 & 0 & 0 & 0 & 0 & 0 & 0 & 0 & 0 & 10 & $9 \%$ \\
\hline 20. & 0 & 1 & 8 & 1 & 0 & 0 & 1 & 0 & 1 & 0 & 0 & 12 & $11 \%$ \\
\hline 21. & 10 & 10 & 0 & 0 & 10 & 5 & 10 & 10 & 5 & 0 & 0 & 60 & $55 \%$ \\
\hline 22. & 9 & 5 & 9 & 9 & 0 & 9 & 0 & 0 & 0 & 0 & 0 & 41 & $37 \%$ \\
\hline & & & & & & & & & & \\
\hline
\end{tabular}

\begin{tabular}{|c|c|c|c|c|c|c|c|c|c|c|c|c|c|}
\hline \multicolumn{10}{|c|}{ DIMENSÃO ACESSIBILIDADE ARQUITETÔNICA } \\
\hline ESCOLAS & A1 & A2 & A3 & A4 & A5 & A6 & A7 & A8 & A9 & A10 & A11 & $\begin{array}{c}\text { Pontos } \\
\text { total }\end{array}$ & $\begin{array}{c}\% \text { da } \\
\text { Pontuação } \\
\text { possivel }\end{array}$ \\
\hline 23. & 0 & 0 & 10 & 0 & 0 & 0 & 0 & 0 & 0 & 0 & 5 & 15 & $14 \%$ \\
\hline 24. & 6 & 6 & 7 & 0 & 0 & 0 & 7 & 7 & 0 & 0 & 5 & 38 & $35 \%$ \\
\hline 25. & 10 & 7 & 10 & 10 & 10 & 10 & 0 & 10 & 5 & 0 & 4 & 76 & $69 \%$ \\
\hline 26. & 10 & 0 & 10 & 0 & 0 & 0 & 10 & 0 & 0 & 0 & 10 & 40 & $36 \%$ \\
\hline 27. & 0 & 0 & 4 & 0 & 0 & 0 & 0 & 0 & 0 & 0 & 6 & 10 & $9 \%$ \\
\hline 28. & 8 & 5 & 10 & 5 & 0 & 0 & 5 & 0 & 0 & 0 & 0 & 33 & $30 \%$ \\
\hline 29. & 8 & 8 & 5 & 0 & 0 & 0 & 0 & 0 & 0 & 0 & 0 & 21 & $19 \%$ \\
\hline 30. & 9 & 5 & 9 & 5 & 5 & 5 & 9 & 0 & 2 & 2 & 5 & 56 & $51 \%$ \\
\hline 31. & 0 & 0 & 0 & 0 & 0 & 0 & 0 & 0 & 0 & 0 & 0 & 0 & $0 \%$ \\
\hline 32. & 0 & 0 & 3 & 3 & 3 & 3 & 3 & 3 & 0 & 0 & 0 & 18 & $16 \%$ \\
\hline 33. & 0 & 0 & 8 & 8 & 0 & 0 & 0 & 0 & 0 & 0 & 0 & 16 & $15 \%$ \\
\hline 34. & 10 & 10 & 10 & 10 & 10 & 10 & 5 & 5 & 0 & 0 & 10 & 80 & $73 \%$ \\
\hline 35. & 0 & 0 & 9 & 5 & 10 & 0 & 0 & 0 & 0 & 3 & 4 & 31 & $28 \%$ \\
\hline 36. & 5 & 5 & 10 & 10 & 5 & 0 & 0 & 0 & 0 & 0 & 0 & 35 & $28 \%$ \\
\hline 37. & 9 & 5 & 5 & 9 & 10 & 7 & 7 & 9 & 7 & 0 & 0 & 68 & $62 \%$ \\
\hline
\end{tabular}

Disponível em: https://www.nucleodoconhecimento.com.br/educacao/juiz-de-fora 


\begin{tabular}{|c|c|c|c|c|c|c|c|c|c|c|c|c|c|}
\hline 38. & 0 & 0 & 0 & 0 & 8 & 0 & 0 & 0 & 4 & 0 & 0 & 12 & $11 \%$ \\
\hline 39. & 5 & 5 & 10 & 10 & 5 & 0 & 0 & 0 & 0 & 0 & 0 & 35 & $32 \%$ \\
\hline 40. & 0 & 0 & 0 & 0 & 0 & 0 & 0 & 0 & 0 & 0 & 0 & 0 & $0 \%$ \\
\hline 41. & 2 & 0 & 0 & 3 & 3 & 0 & 4 & 4 & 0 & 0 & 0 & 16 & $15 \%$ \\
\hline 42. & 0 & 0 & 0 & 0 & 0 & 0 & 0 & 0 & 0 & 0 & 0 & 0 & $0 \%$ \\
\hline 43. & 2 & 0 & 0 & 0 & 0 & 0 & 0 & 0 & 3 & 0 & 0 & 5 & $5 \%$ \\
\hline 44. & 9 & 9 & 10 & 10 & 0 & 10 & 0 & 0 & 10 & 8 & 8 & 74 & $67 \%$ \\
\hline 45. & 9 & 7 & 10 & 10 & 10 & 10 & 9 & 5 & 0 & 0 & 10 & 80 & $73 \%$ \\
\hline 46. & 5 & 5 & 10 & 5 & 10 & 0 & 10 & 10 & 5 & 0 & 5 & 65 & $59 \%$ \\
\hline 47. & 0 & 0 & 1 & 1 & 0 & 0 & 10 & 10 & 0 & 0 & 0 & 22 & $20 \%$ \\
\hline 48. & 10 & 8 & 10 & 10 & 0 & 0 & 6 & 6 & 6 & 6 & 6 & 68 & $62 \%$ \\
\hline 49. & 0 & 0 & 5 & 3 & 5 & 2 & 5 & 0 & 0 & 0 & 2 & 22 & $20 \%$ \\
\hline 50. & 9 & 5 & 2 & 2 & 2 & 2 & 0 & 0 & 0 & 0 & 0 & 22 & $20 \%$ \\
\hline 51. & 10 & 10 & 0 & 0 & 0 & 0 & 9 & 5 & 0 & 0 & 5 & 39 & $35 \%$ \\
\hline 52. & 3 & 5 & 5 & 3 & 5 & 5 & 4 & 4 & 0 & 0 & 0 & 34 & $31 \%$ \\
\hline 53. & 5 & 8 & 0 & 0 & 0 & 0 & 7 & 0 & 7 & 7 & 9 & 43 & $39 \%$ \\
\hline 54. & 5 & 5 & 5 & 0 & 0 & 0 & 0 & 0 & 5 & 0 & 0 & 20 & $18 \%$ \\
\hline 55. & 10 & 5 & 10 & 10 & 10 & 10 & 10 & 10 & 0 & 0 & 10 & 85 & $77 \%$ \\
\hline 56. & 5 & 5 & 0 & 8 & 0 & 8 & 0 & 0 & 5 & 0 & 5 & 36 & $33 \%$ \\
\hline 57. & 0 & 0 & 10 & 10 & 5 & 5 & 10 & 0 & 0 & 0 & 5 & 45 & $41 \%$ \\
\hline 58. & 9 & 6 & 9 & 9 & 9 & 9 & 9 & 1 & 1 & 1 & 1 & 64 & $58 \%$ \\
\hline 59. & 10 & 10 & 10 & 10 & 10 & 10 & 10 & 10 & 0 & 0 & 5 & 85 & $77 \%$ \\
\hline 60. & 10 & 4 & 10 & 10 & 10 & 10 & 4 & 4 & 0 & 0 & 5 & 67 & $61 \%$ \\
\hline 61. & 0 & 0 & 5 & 0 & 0 & 5 & 0 & 0 & 5 & 0 & 10 & 25 & $23 \%$ \\
\hline 62. & 0 & 0 & 0 & 0 & 0 & 0 & 0 & 0 & 0 & 0 & 0 & 0 & $0 \%$ \\
\hline 63. & 0 & 5 & 0 & 0 & 0 & 0 & 0 & 0 & 0 & 0 & 0 & 5 & $5 \%$ \\
\hline 64. & 0 & 5 & 8 & 8 & 8 & 5 & 8 & 5 & 0 & 0 & 4 & 51 & $46 \%$ \\
\hline 65. & 10 & 10 & 10 & 0 & 10 & 10 & 0 & 10 & 0 & 10 & 0 & 70 & $64 \%$ \\
\hline & & & & & & & & & & & \\
\hline
\end{tabular}

\begin{tabular}{|c|c|c|c|c|c|c|c|c|c|c|c|c|c|}
\hline \multicolumn{10}{|c|}{ DIMENSÃO: ACESSIBIIDADE ARQUITETỐNICA } \\
\hline ESCOLAS & A1 & A2 & A3 & A4 & A5 & A6 & A7 & A8 & A9 & A10 & A11 & $\begin{array}{c}\text { Pontos } \\
\text { total }\end{array}$ & $\begin{array}{c}\% \text { da } \\
\text { Pontuação } \\
\text { possivel }\end{array}$ \\
\hline 66. & 0 & 0 & 0 & 0 & 0 & 0 & 0 & 0 & 0 & 0 & 0 & 0 & $0 \%$ \\
\hline 67. & 0 & 0 & 0 & 0 & 0 & 0 & 0 & 0 & 0 & 0 & 0 & 0 & $0 \%$ \\
\hline 68. & 0 & 0 & 6 & 10 & 10 & 0 & 0 & 6 & 0 & 0 & 0 & 32 & $29 \%$ \\
\hline 69. & 5 & 10 & 10 & 5 & 5 & 10 & 0 & 0 & 5 & 0 & 10 & 60 & $55 \%$ \\
\hline 70. & 0 & 0 & 10 & 0 & 10 & 0 & 0 & 0 & 0 & 0 & 5 & 25 & $23 \%$ \\
\hline Total & 322 & 246 & 356 & 262 & 258 & 216 & 253 & 188 & 111 & 47 & 178 & & $\begin{array}{c}\text { Média da } \\
\text { Pontuação } \\
\text { Possivel }\end{array}$ \\
\hline $\begin{array}{c}\text { \% da } \\
\text { Pontuação } \\
\text { possivel }\end{array}$ & $46 \%$ & $35 \%$ & $51 \%$ & $37 \%$ & $37 \%$ & $31 \%$ & $36 \%$ & $27 \%$ & $16 \%$ & $7 \%$ & $25 \%$ & $\begin{array}{c}\text { Módia da } \\
\text { Pontuação } \\
\text { Possivel }\end{array}$ & $32 \%$ \\
\hline
\end{tabular}

Fonte: Elaborado pela pesquisadora

Disponível em: https://www.nucleodoconhecimento.com.br/educacao/juiz-de-fora 
$\mathrm{Na}$ acessibilidade arquitetônica, foi possível identificar que a variável piso tátil (A10) recebeu baixíssima pontuação por parte das escolas, 47 pontos em possíveis 700 . A pesquisa também demonstrou grande incidência de desníveis (A11) presentes na maioria das escolas, 178 pontos em possíveis 700 , ficando somente rampa para a entrada (A3) com o índice acima de 50\%. Ressaltou-se a inexistência de acessibilidade arquitetônica, a partir do momento que houve predomínio de pontuações abaixo de $50 \%$.

- ACESSIBILIDADE METODOLÓGICA: analisadas as sub divisões das variáveis: profissionais com formação especifica (M1), adequação no ambiente escolar (M2), adequação dos métodos de ensino (M3), adequação das modalidades de ensino (M4), atendimento educacional especializado (M5), bidocência (M6), estagiários (M7), laboratório de aprendizagem (M8), projetos diversos (M9).

Tabela 2 - Pontuações das escolas nas subdivisões das variáveis da Acessibilidade Metodológica 


\begin{tabular}{|c|c|c|c|c|c|c|c|c|c|c|c|}
\hline \multicolumn{12}{|c|}{ DIMENSÃO: ACESSIBILIDADE METODOLÓGICA } \\
\hline ESCOLAS & M1 & M2 & M3 & M4 & M5 & M6 & M7 & M8 & M9 & Pontos & $\begin{array}{c}\text { \% da Pontuação } \\
\text { possivel }\end{array}$ \\
\hline 1. & 10 & 10 & 10 & 10 & 10 & 10 & 10 & 10 & 10 & 90 & $100 \%$ \\
\hline 2. & 10 & 10 & 10 & 10 & 10 & 10 & 10 & 10 & 10 & 90 & $100 \%$ \\
\hline 3. & 5 & 7 & 5 & 7 & 6 & 7 & 7 & 7 & 7 & 58 & $64 \%$ \\
\hline 4. & 0 & 2 & 2 & 0 & 8 & 9 & 8 & 8 & 8 & 45 & $50 \%$ \\
\hline 5. & 7 & 7 & 8 & 8 & 0 & 10 & 0 & 10 & 10 & 60 & $67 \%$ \\
\hline 6. & 5 & 5 & 5 & 5 & 7 & 0 & 0 & 8 & 6 & 41 & $46 \%$ \\
\hline 7. & 0 & 0 & 3 & 3 & 1 & 0 & 1 & 1 & 3 & 12 & $13 \%$ \\
\hline 8. & 10 & 10 & 10 & 10 & 0 & 0 & 0 & 0 & 0 & 40 & $44 \%$ \\
\hline \multicolumn{12}{|c|}{ DIMENSÃO: ACESSIBILIDADE METODOLÓGICA } \\
\hline ESCOLAS & M1 & M2 & M3 & M4 & M5 & M6 & M7 & M8 & M9 & Pontos & $\begin{array}{c}\% \text { da } \\
\text { Pontuação } \\
\text { possível }\end{array}$ \\
\hline 9. & 6 & 1 & 3 & 7 & 1 & 7 & 7 & 1 & 1 & 34 & $38 \%$ \\
\hline 10. & 8 & 8 & 10 & 10 & 10 & 5 & 0 & 8 & 9 & 68 & $76 \%$ \\
\hline 11. & 5 & 6 & 6 & 6 & 5 & 7 & 7 & 5 & 8 & 55 & $61 \%$ \\
\hline 12. & 0 & 1 & 1 & 1 & 1 & 0 & 0 & 2 & 2 & 8 & $9 \%$ \\
\hline 13. & 2 & 5 & 5 & 8 & 9 & 9 & 5 & 2 & 7 & 52 & $58 \%$ \\
\hline 14. & 0 & 0 & 5 & 0 & 10 & 2 & 0 & 0 & 5 & 22 & $24 \%$ \\
\hline 15. & 7 & 5 & 8 & 8 & 10 & 10 & 10 & 10 & 10 & 78 & $87 \%$ \\
\hline 16. & 9 & 0 & 8 & 8 & 10 & 10 & 9 & 8 & 9 & 71 & $79 \%$ \\
\hline 17. & 10 & 5 & 8 & 8 & 8 & 0 & 0 & 10 & 10 & 59 & $66 \%$ \\
\hline 18. & 5 & 5 & 5 & 7 & 2 & 0 & 0 & 5 & 8 & 37 & $41 \%$ \\
\hline 19. & 8 & 8 & 10 & 10 & 0 & 10 & 0 & 10 & 10 & 66 & $73 \%$ \\
\hline 20. & 9 & 3 & 5 & 5 & 7 & 8 & 3 & 8 & 3 & 51 & $57 \%$ \\
\hline 21. & 5 & 5 & 5 & 5 & 6 & 5 & 10 & 10 & 10 & 61 & $68 \%$ \\
\hline 22. & 1 & 4 & 4 & 4 & 1 & 0 & 2 & 4 & 4 & 24 & $27 \%$ \\
\hline 23. & 10 & 6 & 2 & 2 & 8 & 10 & 0 & 10 & 10 & 58 & $64 \%$ \\
\hline 24. & 6 & 5 & 0 & 0 & 0 & 0 & 0 & 0 & 0 & 11 & $12 \%$ \\
\hline 25. & 7 & 8 & 8 & 8 & 7 & 10 & 0 & 10 & 10 & 68 & $76 \%$ \\
\hline 26. & 10 & 10 & 10 & 10 & 10 & 10 & 0 & 10 & 10 & 80 & $89 \%$ \\
\hline 27. & 0 & 0 & 8 & 6 & 10 & 10 & 6 & 10 & 10 & 60 & $67 \%$ \\
\hline 28. & 5 & 5 & 4 & 3 & 0 & 0 & 0 & 5 & 9 & 31 & $34 \%$ \\
\hline 29. & 10 & 0 & 5 & 5 & 10 & 2 & 0 & 5 & 5 & 42 & $47 \%$ \\
\hline 30. & 9 & 5 & 9 & 5 & 7 & 9 & 0 & 10 & 10 & 64 & $71 \%$ \\
\hline 31. & 3 & 3 & 3 & 10 & 0 & 7 & 0 & 0 & 0 & 26 & $29 \%$ \\
\hline 32. & 0 & 5 & 5 & 5 & 5 & 5 & 0 & 8 & 8 & 41 & $46 \%$ \\
\hline 33. & 3 & 3 & 3 & 2 & 0 & 0 & 0 & 0 & 0 & 11 & $12 \%$ \\
\hline 34. & 10 & 10 & 10 & 10 & 10 & 10 & 2 & 10 & 5 & 77 & $86 \%$ \\
\hline 35. & 4 & 0 & 4 & 4 & 0 & 10 & 0 & 5 & 5 & 32 & $36 \%$ \\
\hline 36. & 10 & 5 & 10 & 10 & 10 & 10 & 0 & 5 & 5 & 65 & $72 \%$ \\
\hline 37. & 9 & 9 & 6 & 8 & 10 & 10 & 0 & 9 & 10 & 71 & $79 \%$ \\
\hline 38. & 2 & 6 & 6 & 6 & 7 & 8 & 8 & 8 & 8 & 59 & $66 \%$ \\
\hline
\end{tabular}




\begin{tabular}{|c|c|c|c|c|c|c|c|c|c|c|c|}
\hline 39. & 10 & 5 & 10 & 10 & 10 & 10 & 0 & 5 & 5 & 65 & $72 \%$ \\
\hline 40. & 8 & 8 & 6 & 8 & 8 & 10 & 0 & 0 & 10 & 58 & $64 \%$ \\
\hline 41. & 0 & 5 & 5 & 5 & 0 & 0 & 0 & 4 & 4 & 23 & $26 \%$ \\
\hline 42. & 3 & 7 & 7 & 7 & 4 & 0 & 0 & 0 & 7 & 35 & $39 \%$ \\
\hline 43. & 6 & 3 & 7 & 4 & 7 & 8 & 0 & 8 & 4 & 47 & $52 \%$ \\
\hline 44. & 10 & 9 & 9 & 9 & 10 & 10 & 10 & 10 & 10 & 87 & $97 \%$ \\
\hline 45. & 9 & 9 & 9 & 9 & 10 & 10 & 10 & 10 & 10 & 86 & $96 \%$ \\
\hline 46. & 5 & 8 & 8 & 8 & 8 & 10 & 10 & 8 & 8 & 73 & $81 \%$ \\
\hline 47. & 0 & 0 & 0 & 10 & 10 & 10 & 0 & 10 & 10 & 50 & $56 \%$ \\
\hline 48. & 3 & 3 & 3 & 3 & 8 & 6 & 6 & 0 & 10 & 42 & $47 \%$ \\
\hline 49. & 5 & 5 & 3 & 3 & 7 & 7 & 7 & 1 & 5 & 43 & $48 \%$ \\
\hline \multicolumn{12}{|c|}{ DIMENSÃO: ACESSIBILIDADE METODOLÓGICA } \\
\hline ESCOLAS & M1 & M2 & M3 & M4 & M5 & M6 & M7 & M8 & M9 & Pontos & $\begin{array}{c}\text { \% da } \\
\text { Pontuação } \\
\text { possível }\end{array}$ \\
\hline 50. & 2 & 2 & 2 & 2 & 0 & 2 & 0 & 0 & 2 & 12 & $13 \%$ \\
\hline 51. & 10 & 7 & 9 & 9 & 10 & 10 & 0 & 10 & 10 & 75 & $83 \%$ \\
\hline 52. & 0 & 3 & 4 & 4 & 4 & 9 & 9 & 5 & 7 & 45 & $50 \%$ \\
\hline 53. & 9 & 9 & 7 & 10 & 10 & 9 & 10 & 10 & 10 & 84 & $93 \%$ \\
\hline 54. & 5 & 2 & 5 & 5 & 5 & 5 & 0 & 0 & 5 & 32 & $36 \%$ \\
\hline 55. & 0 & 10 & 0 & 0 & 0 & 10 & 0 & 10 & 5 & 35 & $39 \%$ \\
\hline 56. & 5 & 5 & 5 & 3 & 9 & 7 & 0 & 9 & 4 & 47 & $52 \%$ \\
\hline 57. & 0 & 0 & 0 & 0 & 0 & 10 & 0 & 0 & 0 & 10 & $11 \%$ \\
\hline 58. & 8 & 4 & 7 & 5 & 9 & 10 & 10 & 10 & 10 & 73 & $81 \%$ \\
\hline 59. & 5 & 5 & 5 & 10 & 10 & 7 & 3 & 7 & 10 & 62 & $69 \%$ \\
\hline 60. & 9 & 10 & 9 & 9 & 0 & 10 & 0 & 10 & 10 & 67 & $74 \%$ \\
\hline 61. & 8 & 0 & 8 & 8 & 8 & 10 & 10 & 10 & 10 & 72 & $80 \%$ \\
\hline 62. & 4 & 2 & 10 & 10 & 0 & 0 & 0 & 0 & 4 & 30 & $33 \%$ \\
\hline 63. & 4 & 2 & 10 & 10 & 0 & 0 & 0 & 0 & 4 & 30 & $33 \%$ \\
\hline 64. & 5 & 5 & 4 & 5 & 5 & 5 & 0 & 5 & 4 & 38 & $42 \%$ \\
\hline 65. & 10 & 10 & 10 & 10 & 10 & 10 & 0 & 10 & 10 & 80 & $89 \%$ \\
\hline 66. & 0 & 4 & 2 & 4 & 4 & 7 & 7 & 7 & 7 & 42 & $47 \%$ \\
\hline 67. & 0 & 0 & 5 & 5 & 0 & 0 & 0 & 8 & 9 & 27 & $30 \%$ \\
\hline 68. & 0 & 0 & 0 & 0 & 0 & 10 & 0 & 0 & 0 & 10 & $11 \%$ \\
\hline 69. & 10 & 8 & 8 & 8 & 10 & 10 & 5 & 10 & 10 & 79 & $88 \%$ \\
\hline 70. & 0 & 5 & 5 & 5 & 1 & 0 & 0 & 10 & 5 & 31 & $34 \%$ \\
\hline Total & 373 & 342 & 411 & 432 & 393 & 452 & 202 & 429 & 474 & & $\begin{array}{c}\text { Média da } \\
\text { Pontuação } \\
\text { Possivel }\end{array}$ \\
\hline $\begin{array}{l}\text { \% da Pontuação } \\
\text { possivel }\end{array}$ & $53 \%$ & $49 \%$ & $59 \%$ & $62 \%$ & $56 \%$ & $65 \%$ & $29 \%$ & $61 \%$ & $68 \%$ & $\begin{array}{c}\text { Média da } \\
\text { Pontuação possivel }\end{array}$ & $56 \%$ \\
\hline
\end{tabular}

FONTE: Elaborada pelos pesquisadores 
A acessibilidade metodológica foi constituída de 9 variáveis que corresponderam a 90 pontos totais por escola o que dá uma média simples de 45 pontos para atingir $50 \%$ do total. Segundo a tabela 2, duas escolas atingiram pontuação máxima de 90 pontos, seguem-se duas escolas com 87 pontos e 86 pontos. Dentre as 70 escolas, 30 não alcançaram $50 \%$ dos pontos distribuídos entre as variáveis.

A diferença de pontuação entre os totais alcançados por cada variável de maior pontuação A9 (projetos diversos) e a de menor pontuação A7 (estagiários) foi de 202 pontos, a de menor pontuação alcançou somente $29 \%$ do total e a maior pontuação alcançou $68 \%$ do total. Observa-se que somente duas variáveis obtiveram pontuação inferior a $50 \%$, contudo as demais não ultrapassaram a barreira dos $70 \%$.

- ACESSIBILIDADE INSTRUMENTAL: analisada as sub divisões das variáveis: adequação dos materiais pedagógicos (I1), adequação do mobiliário escolar (12), jogos próprios para inclusão (I3), computadores para uso dos educandos (14), laptop para uso em salas de aula (15), data show (16), aparelho de som (17), Tv's e DVD's (18).

Tabela 3 - Pontuações das escolas nas subdivisões das variáveis da Acessibilidade Instrumental 


\begin{tabular}{|c|c|c|c|c|c|c|c|c|c|c|}
\hline \multicolumn{11}{|c|}{ DIMENSÃO: ACESSIBILIDADE INSTRUMENTAL } \\
\hline ESCOLAS & I1 & I2 & I3 & I4 & I5 & I6 & I7 & I8 & Pontos & $\begin{array}{c}\text { \% da Pontuação } \\
\text { possivel }\end{array}$ \\
\hline 1. & 10 & 10 & 10 & 10 & 10 & 10 & 10 & 10 & 80 & $100 \%$ \\
\hline 2. & 10 & 10 & 10 & 10 & 0 & 10 & 10 & 10 & 70 & $88 \%$ \\
\hline 3. & 7 & 6 & 7 & 7 & 0 & 7 & 7 & 8 & 49 & $61 \%$ \\
\hline 4. & 8 & 3 & 6 & 5 & 0 & 8 & 9 & 8 & 47 & $59 \%$ \\
\hline 5. & 8 & 5 & 8 & 0 & 0 & 10 & 10 & 10 & 51 & $64 \%$ \\
\hline 6. & 5 & 2 & 1 & 7 & 0 & 9 & 8 & 8 & 40 & $50 \%$ \\
\hline 7. & 2 & 0 & 3 & 1 & 0 & 0 & 2 & 2 & 10 & $13 \%$ \\
\hline 8. & 10 & 10 & 0 & 10 & 0 & 10 & 10 & 10 & 60 & $75 \%$ \\
\hline 9. & 7 & 1 & 7 & 0 & 6 & 6 & 6 & 5 & 38 & $48 \%$ \\
\hline 10. & 10 & 10 & 6 & 10 & 0 & 10 & 10 & 10 & 66 & $83 \%$ \\
\hline 11. & 8 & 8 & 6 & 2 & 2 & 10 & 10 & 10 & 56 & $70 \%$ \\
\hline 12. & 1 & 0 & 2 & 5 & 0 & 5 & 4 & 3 & 20 & $25 \%$ \\
\hline 13. & 8 & 3 & 3 & 10 & 0 & 10 & 8 & 10 & 52 & $65 \%$ \\
\hline 14. & 7 & 5 & 0 & 5 & 0 & 5 & 5 & 5 & 32 & $40 \%$ \\
\hline 15. & 10 & 8 & 9 & 10 & 10 & 10 & 10 & 10 & 77 & $96 \%$ \\
\hline 16. & 9 & 3 & 9 & 7 & 2 & 10 & 7 & 5 & 52 & $65 \%$ \\
\hline 17. & 8 & 10 & 8 & 10 & 10 & 10 & 10 & 10 & 76 & $95 \%$ \\
\hline 18. & 3 & 3 & 3 & 9 & 0 & 9 & 9 & 9 & 45 & $56 \%$ \\
\hline 19. & 10 & 5 & 10 & 10 & 0 & 10 & 10 & 10 & 65 & $81 \%$ \\
\hline 20. & 8 & 0 & 8 & 7 & 9 & 9 & 7 & 7 & 55 & $69 \%$ \\
\hline 21. & 10 & 10 & 10 & 10 & 0 & 10 & 10 & 10 & 70 & $88 \%$ \\
\hline 22. & 0 & 4 & 2 & 7 & 0 & 7 & 7 & 7 & 34 & $43 \%$ \\
\hline 23. & 0 & 0 & 0 & 6 & 0 & 10 & 10 & 10 & 36 & $45 \%$ \\
\hline 24. & 7 & 7 & 0 & 0 & 0 & 10 & 10 & 10 & 44 & $55 \%$ \\
\hline 25. & 8 & 10 & 8 & 10 & 0 & 10 & 10 & 10 & 66 & $83 \%$ \\
\hline 26. & 10 & 10 & 10 & 10 & 10 & 10 & 10 & 10 & 80 & $100 \%$ \\
\hline 27. & 7 & 6 & 10 & 5 & 2 & 10 & 10 & 10 & 60 & $75 \%$ \\
\hline 28. & 7 & 0 & 3 & 10 & 4 & 10 & 10 & 10 & 54 & $68 \%$ \\
\hline 29. & 8 & 0 & 5 & 10 & 10 & 10 & 10 & 10 & 63 & $79 \%$ \\
\hline 30. & 7 & 3 & 7 & 10 & 0 & 9 & 10 & 10 & 56 & $70 \%$ \\
\hline 31. & 5 & 0 & 0 & 10 & 0 & 10 & 10 & 10 & 45 & $56 \%$ \\
\hline 32. & 8 & 5 & 0 & 0 & 0 & 5 & 0 & 5 & 23 & $29 \%$ \\
\hline 33. & 2 & 0 & 1 & 0 & 0 & 0 & 10 & 10 & 23 & $29 \%$ \\
\hline
\end{tabular}


CONHECIMENTO https://www.nucleodoconhecimento.com.br

\begin{tabular}{|c|c|c|c|c|c|c|c|c|c|c|}
\hline \multicolumn{10}{|c|}{ DIMENSÃO: ACESSIBILIDADE INSTRUMENTAL } \\
\hline ESCOLAS & I1 & I2 & I3 & I4 & I5 & I6 & I7 & I8 & Pontos & $\begin{array}{c}\text { \% da Pontuação } \\
\text { possivel }\end{array}$ \\
\hline 34. & 8 & 8 & 5 & 2 & 0 & 1 & 10 & 3 & 37 & $46 \%$ \\
\hline 35. & 5 & 0 & 0 & 5 & 0 & 10 & 10 & 10 & 40 & $50 \%$ \\
\hline 36. & 5 & 5 & 5 & 10 & 10 & 10 & 5 & 5 & 55 & $69 \%$ \\
\hline 37. & 10 & 9 & 9 & 10 & 2 & 10 & 10 & 10 & 70 & $88 \%$ \\
\hline 38. & 8 & 8 & 8 & 7 & 0 & 10 & 8 & 10 & 59 & $74 \%$ \\
\hline 39. & 5 & 5 & 5 & 10 & 10 & 10 & 5 & 5 & 55 & $69 \%$ \\
\hline 40. & 10 & 10 & 10 & 10 & 0 & 10 & 10 & 10 & 70 & $88 \%$ \\
\hline
\end{tabular}




\begin{tabular}{|c|c|c|c|c|c|c|c|c|c|c|}
\hline 41. & 5 & 4 & 5 & 7 & 0 & 5 & 5 & 5 & 36 & $45 \%$ \\
\hline 42. & 7 & 0 & 3 & 0 & 0 & 10 & 10 & 10 & 40 & $50 \%$ \\
\hline 43. & 7 & 8 & 7 & 8 & 0 & 0 & 8 & 8 & 46 & $58 \%$ \\
\hline 44. & 9 & 8 & 9 & 9 & 0 & 10 & 10 & 10 & 65 & $81 \%$ \\
\hline 45. & 9 & 9 & 10 & 9 & 0 & 10 & 10 & 10 & 67 & $84 \%$ \\
\hline 46. & 8 & 5 & 5 & 5 & 8 & 10 & 5 & 8 & 54 & $68 \%$ \\
\hline 47. & 10 & 0 & 0 & 10 & 0 & 10 & 10 & 10 & 50 & $63 \%$ \\
\hline 48. & 6 & 10 & 10 & 10 & 0 & 10 & 10 & 10 & 66 & $83 \%$ \\
\hline 49. & 7 & 6 & 6 & 6 & 2 & 7 & 7 & 7 & 48 & $60 \%$ \\
\hline 50. & 2 & 2 & 2 & 8 & 0 & 0 & 2 & 2 & 18 & $23 \%$ \\
\hline 51. & 10 & 8 & 9 & 10 & 5 & 9 & 8 & 9 & 68 & $85 \%$ \\
\hline 52. & 8 & 3 & 8 & 0 & 0 & 10 & 10 & 5 & 44 & $55 \%$ \\
\hline 53. & 9 & 9 & 9 & 10 & 0 & 10 & 10 & 10 & 67 & $84 \%$ \\
\hline 54. & 5 & 0 & 5 & 5 & 0 & 9 & 9 & 9 & 42 & $53 \%$ \\
\hline 55. & 7 & 10 & 5 & 0 & 0 & 10 & 10 & 10 & 52 & $65 \%$ \\
\hline 56. & 5 & 0 & 5 & 5 & 0 & 10 & 5 & 10 & 40 & $50 \%$ \\
\hline 57. & 0 & 0 & 0 & 10 & 0 & 10 & 10 & 10 & 40 & $50 \%$ \\
\hline 58. & 10 & 9 & 10 & 10 & 0 & 10 & 10 & 10 & 69 & $86 \%$ \\
\hline 59. & 10 & 10 & 10 & 7 & 7 & 8 & 7 & 10 & 69 & $86 \%$ \\
\hline 60. & 10 & 5 & 10 & 4 & 0 & 1 & 10 & 10 & 50 & $63 \%$ \\
\hline 61. & 10 & 0 & 10 & 8 & 5 & 10 & 10 & 10 & 63 & $79 \%$ \\
\hline 62. & 2 & 3 & 2 & 0 & 0 & 5 & 5 & 5 & 22 & $28 \%$ \\
\hline 63. & 4 & 4 & 0 & 5 & 0 & 5 & 5 & 5 & 28 & $35 \%$ \\
\hline 64. & 7 & 4 & 4 & 5 & 5 & 5 & 5 & 5 & 40 & $50 \%$ \\
\hline 65. & 10 & 10 & 10 & 10 & 0 & 0 & 0 & 0 & 40 & $50 \%$ \\
\hline 66. & 5 & 0 & 0 & 10 & 0 & 10 & 10 & 10 & 45 & $56 \%$ \\
\hline 67. & 5 & 0 & 5 & 8 & 0 & 10 & 10 & 5 & 43 & $54 \%$ \\
\hline 68. & 0 & 0 & 0 & 0 & 0 & 10 & 10 & 8 & 28 & $35 \%$ \\
\hline 69. & 10 & 10 & 10 & 10 & 0 & 10 & 10 & 10 & 70 & $88 \%$ \\
\hline 70. & 1 & 0 & 0 & 5 & 0 & 10 & 10 & 10 & 36 & $45 \%$ \\
\hline Total & 477 & 339 & 383 & 471 & 129 & 574 & 578 & 576 & & $\begin{array}{c}\text { Média da Pontuação } \\
\text { Possivel }\end{array}$ \\
\hline $\begin{array}{l}\text { \% da Pontuação } \\
\text { possivel }\end{array}$ & $68 \%$ & $48 \%$ & $55 \%$ & $67 \%$ & $18 \%$ & $82 \%$ & $83 \%$ & $82 \%$ & $\begin{array}{l}\text { Média da Pontuação } \\
\text { Possível }\end{array}$ & $63 \%$ \\
\hline
\end{tabular}

Fonte: Elaborado pela pesquisadora

Para avaliação da acessibilidade instrumental foram estudados os dados reunidos na tabela 3. Os dados da última coluna desta tabela mostram que 30 escolas não atingiram $50 \%$ do total das notas distribuídas e a escola de menor pontuação atingiu $23 \%$ do total de pontuação. As outras 40 escolas ficaram acima de $50 \%$, sendo que somente duas dentre elas atingiram $100 \%$ da pontuação, a diferença entre as melhores notas e a mais baixa perfaz um total de $77 \%$. 
A comparação entre as variáveis demonstra que o fator de menor pontuação é o 15 (laptop para uso em sala), com 18\% da pontuação total e a variável 17 (aparelho de som) com $83 \%$ do total da pontuação, perfaz uma diferença de $65 \%$.

- ACESSIBILIDADE COMUNICACIONAL: analisadas as sub divisões das variáveis: utilização de comunicação alternativa (C1), utilização da Libras no contexto de sala de aula (C2), utilização de braille no contexto de sala de aula (C3), grupos de estudo sobre deficiências (C4), grupos de estudo sobre diversidade (C5), conscientização dos funcionários (C6), conscientização da comunidade escolar (C7), uso de sinalização e desenho universal (C8).

Tabela 4 - Pontuações das escolas nas subdivisões das variáveis da acessibilidade comunicacional 


\begin{tabular}{|c|c|c|c|c|c|c|c|c|c|c|}
\hline \multicolumn{11}{|c|}{ DIMENSÃO: ACESSIBILIDADE COMUNICACIONAL } \\
\hline ESCOLAS & $\mathrm{C} 1$ & $\mathrm{C} 2$ & $\mathrm{C} 3$ & $\mathrm{C} 4$ & $\mathrm{C} 5$ & $\mathrm{C} 6$ & $\mathrm{C} 7$ & $\mathrm{C} 8$ & Pontos & \% da Pontuação possível \\
\hline 1. & 5 & 0 & 0 & 5 & 5 & 5 & 10 & 0 & 30 & $38 \%$ \\
\hline 2. & 10 & 10 & 0 & 0 & 0 & 10 & 10 & 0 & 40 & $50 \%$ \\
\hline 3. & 0 & 0 & 0 & 0 & 6 & 5 & 5 & 5 & 21 & $26 \%$ \\
\hline 4. & 0 & 0 & 0 & 0 & 0 & 5 & 5 & 5 & 15 & $19 \%$ \\
\hline 5 . & 7 & 0 & 0 & 6 & 6 & 10 & 10 & 4 & 43 & $54 \%$ \\
\hline 6. & 5 & 1 & 1 & 1 & 1 & 2 & 3 & 3 & 17 & $21 \%$ \\
\hline 7. & 2 & 1 & 0 & 3 & 3 & 4 & 4 & 4 & 21 & $26 \%$ \\
\hline 8. & 10 & 0 & 0 & 0 & 10 & 10 & 10 & 8 & 48 & $60 \%$ \\
\hline 9. & 7 & 1 & 1 & 1 & 5 & 1 & 1 & 1 & 18 & $23 \%$ \\
\hline 10. & 9 & 10 & 0 & 9 & 9 & 10 & 10 & 10 & 67 & $84 \%$ \\
\hline 11. & 5 & 3 & 3 & 5 & 8 & 3 & 5 & 3 & 35 & $44 \%$ \\
\hline 12. & 0 & 0 & 0 & 0 & 0 & 0 & 0 & 0 & 0 & $0 \%$ \\
\hline 13. & 0 & 0 & 0 & 0 & 0 & 5 & 7 & 0 & 12 & $15 \%$ \\
\hline 14. & 0 & 0 & 0 & 0 & 5 & 5 & 5 & 0 & 15 & $19 \%$ \\
\hline 15. & 10 & 10 & 0 & 5 & 5 & 8 & 8 & 8 & 54 & $68 \%$ \\
\hline 16. & 4 & 0 & 0 & 4 & 5 & 8 & 9 & 5 & 35 & $44 \%$ \\
\hline 17. & 10 & 10 & 10 & 9 & 9 & 10 & 9 & 9 & 76 & $95 \%$ \\
\hline 18. & 5 & 0 & 0 & 0 & 3 & 5 & 7 & 5 & 25 & $31 \%$ \\
\hline 19. & 0 & 0 & 0 & 5 & 5 & 8 & 8 & 0 & 26 & $33 \%$ \\
\hline \multicolumn{11}{|c|}{ DIMENSẪO: ACESSIBILIDADE COMUNICACIONAL } \\
\hline$\overline{\text { ESCOLAS }}$ & $\mathrm{C} 1$ & $\mathrm{C} 2$ & $\mathrm{C} 3$ & $\mathrm{C} 4$ & $\mathrm{C} 5$ & $\overline{\mathrm{C} 6}$ & C7 & $\mathrm{C} 8$ & Pontos & $\%$ da Pontuação possível \\
\hline 20. & 1 & 0 & 9 & 6 & 1 & 6 & 6 & 2 & 31 & $39 \%$ \\
\hline 21. & 5 & 5 & 0 & 5 & 5 & 5 & 10 & 5 & 40 & $50 \%$ \\
\hline 22. & 0 & 0 & 0 & 0 & 4 & 3 & 3 & 1 & 11 & $14 \%$ \\
\hline 23. & 5 & 7 & 0 & 0 & 0 & 4 & 6 & 7 & 29 & $36 \%$ \\
\hline 24. & 0 & 5 & 0 & 0 & 0 & 7 & 7 & 0 & 19 & $24 \%$ \\
\hline 25. & 10 & 0 & 0 & 10 & 10 & 10 & 10 & 0 & 50 & $63 \%$ \\
\hline 26. & 10 & 5 & 5 & 9 & 10 & 10 & 10 & 0 & 59 & $74 \%$ \\
\hline 27. & 2 & 0 & 0 & 4 & 6 & 9 & 8 & 0 & 29 & $36 \%$ \\
\hline 28. & 4 & 0 & 0 & 0 & 0 & 3 & 3 & 3 & 13 & $16 \%$ \\
\hline 29. & 0 & 0 & 0 & 0 & 0 & 1 & 5 & 0 & 6 & $8 \%$ \\
\hline 30. & 8 & 10 & 0 & 0 & 8 & 10 & 9 & 5 & 50 & $63 \%$ \\
\hline 31. & 0 & 0 & 0 & 0 & 10 & 3 & 10 & 0 & 23 & $29 \%$ \\
\hline 32. & 0 & 0 & 0 & 0 & 0 & 0 & 5 & 0 & 5 & $6 \%$ \\
\hline 33. & 0 & 0 & 0 & 0 & 7 & 5 & 2 & 0 & 14 & $18 \%$ \\
\hline 34. & 5 & 1 & 1 & 0 & 0 & 6 & 6 & 3 & 22 & $28 \%$ \\
\hline 35. & 5 & 10 & 0 & 5 & 5 & 5 & 8 & 5 & 43 & $54 \%$ \\
\hline 36. & 5 & 0 & 0 & 0 & 0 & 5 & 10 & 0 & 20 & $25 \%$ \\
\hline 37. & 1 & 0 & 0 & 3 & 5 & 7 & 10 & 2 & 28 & $35 \%$ \\
\hline 38. & 6 & 0 & 0 & 0 & 3 & 3 & 6 & 0 & 18 & $23 \%$ \\
\hline 39. & 5 & 0 & 0 & 0 & 0 & 5 & 10 & 0 & 20 & $25 \%$ \\
\hline 40. & 10 & 0 & 0 & 8 & 8 & 10 & 10 & 10 & 56 & $70 \%$ \\
\hline
\end{tabular}




\begin{tabular}{|c|c|c|c|c|c|c|c|c|c|c|}
\hline 41. & 5 & 0 & 0 & 0 & 0 & 4 & 4 & 0 & 13 & $16 \%$ \\
\hline 42. & 3 & 3 & 3 & 7 & 7 & 10 & 10 & 2 & 45 & $56 \%$ \\
\hline 43. & 5 & 7 & 0 & 7 & 7 & 5 & 8 & 0 & 39 & $49 \%$ \\
\hline 44. & 9 & 10 & 0 & 0 & 0 & 9 & 9 & 7 & 44 & $55 \%$ \\
\hline 45. & 4 & 5 & 0 & 3 & 3 & 5 & 8 & 8 & 36 & $45 \%$ \\
\hline 46. & 0 & 8 & 0 & 8 & 8 & 8 & 8 & 2 & 42 & $53 \%$ \\
\hline 47. & 0 & 10 & 0 & 0 & 0 & 0 & 0 & 0 & 10 & $13 \%$ \\
\hline 48. & 10 & 0 & 0 & 2 & 2 & 2 & 2 & 0 & 18 & $23 \%$ \\
\hline 49. & 2 & 0 & 0 & 0 & 0 & 4 & 6 & 0 & 12 & $15 \%$ \\
\hline 50. & 0 & 0 & 0 & 0 & 0 & 2 & 2 & 0 & 4 & $5 \%$ \\
\hline 51. & 5 & 0 & 0 & 5 & 5 & 8 & 9 & 8 & 40 & $50 \%$ \\
\hline 52. & 2 & 2 & 2 & 2 & 2 & 5 & 5 & 4 & 24 & $30 \%$ \\
\hline 53. & 7 & 8 & 0 & 10 & 10 & 10 & 10 & 8 & 63 & $79 \%$ \\
\hline 54. & 0 & 0 & 0 & 5 & 5 & 5 & 5 & 0 & 20 & $25 \%$ \\
\hline 55. & 5 & 0 & 0 & 0 & 0 & 3 & 0 & 0 & 8 & $10 \%$ \\
\hline 56. & 5 & 0 & 0 & 10 & 10 & 5 & 5 & 0 & 35 & $44 \%$ \\
\hline 57. & 0 & 0 & 0 & 0 & 0 & 10 & 10 & 0 & 20 & $25 \%$ \\
\hline 58. & 5 & 10 & 0 & 0 & 0 & 6 & 8 & 4 & 33 & $41 \%$ \\
\hline 59. & 10 & 10 & 7 & 10 & 9 & 10 & 10 & 5 & 71 & $89 \%$ \\
\hline 60. & 0 & 0 & 0 & 0 & 0 & 8 & 10 & 0 & 18 & $23 \%$ \\
\hline 61. & 0 & 10 & 0 & 0 & 5 & 5 & 5 & 5 & 30 & $38 \%$ \\
\hline 62. & 0 & 0 & 0 & 0 & 0 & 7 & 7 & 0 & 14 & $18 \%$ \\
\hline \multicolumn{11}{|c|}{ DIMENSÃO: ACESSIBILIDADE COMUNICACIONAL } \\
\hline ESCOLAS & $\mathrm{C} 1$ & $\mathrm{C} 2$ & $\mathrm{C} 3$ & $\mathrm{C} 4$ & $\mathrm{C} 5$ & $\mathrm{C} 6$ & C7 & $\mathrm{C} 8$ & Pontos & \% da Pontuação possível \\
\hline 63. & 0 & 0 & 0 & 0 & 0 & 4 & 4 & 2 & 10 & $13 \%$ \\
\hline 64. & 2 & 2 & 2 & 2 & 2 & 2 & 2 & 0 & 14 & $18 \%$ \\
\hline 65. & 0 & 0 & 0 & 0 & 0 & 0 & 0 & 0 & 0 & $0 \%$ \\
\hline 66. & 0 & 0 & 0 & 0 & 10 & 3 & 10 & 0 & 23 & $29 \%$ \\
\hline 67. & 0 & 0 & 0 & 0 & 0 & 5 & 8 & 0 & 13 & $16 \%$ \\
\hline 68. & 0 & 0 & 0 & 0 & 0 & 0 & 0 & 0 & 0 & $0 \%$ \\
\hline 69. & 9 & 10 & 0 & 5 & 5 & 10 & 10 & 10 & 59 & $74 \%$ \\
\hline 70. & 0 & 0 & 0 & 0 & 0 & 4 & 4 & 0 & 8 & $10 \%$ \\
\hline Total & 259 & 184 & 44 & 179 & 257 & 390 & 459 & 178 & & $\begin{array}{c}\text { Média } \\
\text { da Pontuação Possível }\end{array}$ \\
\hline $\begin{array}{c}\% \text { da } \\
\text { Pontuação } \\
\text { possível }\end{array}$ & $37 \%$ & $26 \%$ & $6 \%$ & $26 \%$ & $37 \%$ & $56 \%$ & $66 \%$ & $25 \%$ & $\begin{array}{l}\text { Média da Pontuação } \\
\text { Possível }\end{array}$ & $35 \%$ \\
\hline
\end{tabular}

Fonte: Elaborado pela pesquisadora

A distribuição da pontuação das variáveis da acessibilidade comunicacional, seguiu o modelo das demais variáveis. Nessa tabela a variável de maior pontuação $\mathrm{C7}$ (conscientização da comunidade escolar), com $66 \%$ do total de pontuação para de menor pontuação C3 (utilização de braille no contexto de sala de aula), com $6 \%$ do 
total, a diferença do percentual atingiu $60 \%$, sendo a maior diferença até agora tabulada.

Os resultados entre as escolas, a tabela 4 aponta para o grande índice de escolas que não atingiram $50 \%$ da pontuação total. Entre as outras escolas que atingiram $50 \%$ ou mais, a de maior pontuação foi a número 59 com 71 pontos, o que perfaz $89 \%$ do total

- ACESSIBILIDADE ATITUDINAL: analisados as sub divisões das variáveis: recepção dos professores (AT1), recepção dos alunos (AT2), relacionamento com professores (AT3), relacionamento com outros alunos (AT4), relacionamento escola-família (AT5).

Tabela 5 - Pontuações das escolas nas subdivisões das variáveis da Acessibilidade Atitudinal 


\begin{tabular}{|c|c|c|c|c|c|c|c|}
\hline \multicolumn{8}{|c|}{ DIMENSÃO: ACESSIBILIDADE ATITUDINAL } \\
\hline ESCOLAS & AT1 & AT2 & AT3 & AT4 & AT5 & Pontos & \% da Pontuação possível \\
\hline 1. & 10 & 10 & 10 & 10 & 9 & 49 & $98 \%$ \\
\hline 2. & 10 & 10 & 10 & 10 & 10 & 50 & $100 \%$ \\
\hline 3. & 5 & 5 & 7 & 7 & 7 & 31 & $62 \%$ \\
\hline 4. & 9 & 9 & 9 & 7 & 9 & 43 & $86 \%$ \\
\hline 5. & 8 & 10 & 10 & 10 & 10 & 48 & $96 \%$ \\
\hline 6. & 3 & 3 & 3 & 5 & 5 & 19 & $38 \%$ \\
\hline 7. & 9 & 9 & 9 & 9 & 9 & 45 & $90 \%$ \\
\hline 8. & 10 & 10 & 10 & 10 & 10 & 50 & $100 \%$ \\
\hline \multicolumn{8}{|c|}{ DIMENSÃO: ACESSIBILIDADE ATITUDINAL } \\
\hline ESCOLAS & AT1 & AT2 & AT3 & AT4 & AT5 & Pontos & \% da Pontuação possível \\
\hline 9. & 7 & 7 & 7 & 7 & 7 & 35 & $70 \%$ \\
\hline 10. & 10 & 10 & 10 & 10 & 10 & 50 & $100 \%$ \\
\hline 11. & 7 & 7 & 7 & 8 & 7 & 36 & $72 \%$ \\
\hline 12. & 0 & 0 & 8 & 7 & 4 & 19 & $38 \%$ \\
\hline 13. & 9 & 9 & 9 & 9 & 9 & 45 & $90 \%$ \\
\hline 14. & 10 & 10 & 10 & 10 & 10 & 50 & $100 \%$ \\
\hline 15. & 10 & 10 & 10 & 10 & 10 & 50 & $100 \%$ \\
\hline 16. & 9 & 9 & 8 & 7 & 3 & 36 & $72 \%$ \\
\hline 17. & 10 & 10 & 10 & 10 & 10 & 50 & $100 \%$ \\
\hline 18. & 8 & 8 & 8 & 8 & 7 & 39 & $78 \%$ \\
\hline 19. & 10 & 10 & 10 & 10 & 10 & 50 & $100 \%$ \\
\hline 20. & 6 & 6 & 6 & 6 & 4 & 28 & $56 \%$ \\
\hline 21. & 10 & 10 & 10 & 10 & 10 & 50 & $100 \%$ \\
\hline
\end{tabular}




\begin{tabular}{|c|c|c|c|c|c|c|c|}
\hline 22. & 5 & 5 & 5 & 5 & 5 & 25 & $50 \%$ \\
\hline 23. & 10 & 10 & 10 & 10 & 1 & 41 & $82 \%$ \\
\hline 24. & 0 & 0 & 0 & 0 & 0 & 0 & $0 \%$ \\
\hline 25. & 10 & 10 & 10 & 10 & 10 & 50 & $100 \%$ \\
\hline 26. & 10 & 10 & 10 & 10 & 10 & 50 & $100 \%$ \\
\hline 27. & 10 & 10 & 10 & 10 & 8 & 48 & $96 \%$ \\
\hline 28. & 5 & 5 & 5 & 5 & 5 & 25 & $50 \%$ \\
\hline 29. & 5 & 5 & 5 & 5 & 5 & 25 & $50 \%$ \\
\hline 30. & 9 & 9 & 10 & 10 & 6 & 44 & $88 \%$ \\
\hline 31. & 10 & 10 & 10 & 10 & 7 & 47 & $94 \%$ \\
\hline 32. & 5 & 5 & 5 & 5 & 5 & 25 & $50 \%$ \\
\hline 33. & 0 & 0 & 0 & 0 & 0 & 0 & $0 \%$ \\
\hline 34. & 9 & 9 & 9 & 10 & 9 & 46 & $92 \%$ \\
\hline 35. & 10 & 10 & 10 & 10 & 8 & 48 & $96 \%$ \\
\hline 36. & 10 & 10 & 10 & 10 & 10 & 50 & $100 \%$ \\
\hline 37. & 9 & 8 & 10 & 9 & 9 & 45 & $90 \%$ \\
\hline 38. & 8 & 8 & 8 & 8 & 7 & 39 & $78 \%$ \\
\hline 39. & 10 & 10 & 10 & 10 & 10 & 50 & $100 \%$ \\
\hline 40. & 10 & 10 & 10 & 10 & 10 & 50 & $100 \%$ \\
\hline 41. & 7 & 7 & 7 & 7 & 7 & 35 & $70 \%$ \\
\hline 42. & 10 & 10 & 7 & 10 & 10 & 47 & $94 \%$ \\
\hline 43. & 6 & 8 & 8 & 8 & 6 & 36 & $72 \%$ \\
\hline 44. & 9 & 9 & 9 & 9 & 9 & 45 & $90 \%$ \\
\hline 45. & 9 & 9 & 9 & 9 & 9 & 45 & $90 \%$ \\
\hline 46. & 8 & 8 & 10 & 8 & 10 & 44 & $88 \%$ \\
\hline 47. & 10 & 10 & 10 & 10 & 10 & 50 & $100 \%$ \\
\hline 48. & 9 & 10 & 9 & 9 & 9 & 46 & $92 \%$ \\
\hline 49. & 4 & 6 & 6 & 6 & 6 & 28 & $56 \%$ \\
\hline 50. & 2 & 2 & 2 & 8 & 8 & 22 & $44 \%$ \\
\hline 51. & 10 & 9 & 9 & 10 & 9 & 47 & $94 \%$ \\
\hline 52. & 8 & 8 & 9 & 7 & 7 & 39 & $78 \%$ \\
\hline
\end{tabular}




\begin{tabular}{|c|c|c|c|c|c|c|c|}
\hline \multicolumn{7}{|c|}{ DIMENS ̃̃O: ACESSIBILIDADE ATITUDINAL } \\
\hline ESCOLAS & AT1 & AT2 & AT3 & AT4 & AT5 & Pontos & $\%$ da Pontuação possivel \\
\hline 53. & 10 & 9 & 9 & 10 & 10 & 48 & $96 \%$ \\
\hline 54. & 7 & 7 & 7 & 6 & 5 & 32 & $64 \%$ \\
\hline 55. & 0 & 0 & 10 & 10 & 10 & 30 & $60 \%$ \\
\hline 56. & 9 & 9 & 9 & 9 & 8 & 44 & $88 \%$ \\
\hline 57. & 8 & 8 & 9 & 9 & 10 & 44 & $88 \%$ \\
\hline 58. & 7 & 7 & 8 & 8 & 8 & 38 & $76 \%$ \\
\hline 59. & 9 & 9 & 9 & 10 & 10 & 47 & $94 \%$ \\
\hline 60. & 10 & 10 & 10 & 10 & 10 & 50 & $100 \%$ \\
\hline 61. & 5 & 4 & 5 & 5 & 5 & 24 & $48 \%$ \\
\hline 62. & 10 & 10 & 10 & 10 & 10 & 50 & $100 \%$ \\
\hline 63. & 10 & 10 & 10 & 10 & 10 & 50 & $100 \%$ \\
\hline 64. & 0 & 8 & 8 & 5 & 8 & 29 & $58 \%$ \\
\hline 65. & 10 & 10 & 10 & 10 & 10 & 50 & $100 \%$ \\
\hline
\end{tabular}

\begin{tabular}{|c|c|c|c|c|c|c|c|}
\hline 66. & 10 & 10 & 10 & 10 & 6 & 46 & $92 \%$ \\
\hline 67. & 9 & 9 & 9 & 9 & 9 & 45 & $90 \%$ \\
\hline 68. & 8 & 8 & 7 & 7 & 8 & 38 & $76 \%$ \\
\hline 69. & 10 & 10 & 10 & 10 & 10 & 50 & $100 \%$ \\
\hline 70. & 10 & 10 & 10 & 10 & 4 & 44 & $88 \%$ \\
\hline Total & 549 & 560 & 583 & 586 & 546 & & $\begin{array}{c}\text { Média da Pontuação } \\
\text { Possível }\end{array}$ \\
\hline \% da Pontuação possível & $78 \%$ & $80 \%$ & $83 \%$ & $84 \%$ & $78 \%$ & $\begin{array}{c}\text { Média da Pontuação } \\
\text { Possivel }\end{array}$ & $81 \%$ \\
\hline
\end{tabular}

\begin{tabular}{|c|c|c|c|c|c|c|c|}
\hline 66. & 10 & 10 & 10 & 10 & 6 & 46 & $92 \%$ \\
\hline 67. & 9 & 9 & 9 & 9 & 9 & 45 & $90 \%$ \\
\hline 68. & 8 & 8 & 7 & 7 & 8 & 38 & $76 \%$ \\
\hline 69. & 10 & 10 & 10 & 10 & 10 & 50 & $100 \%$ \\
\hline 70. & 10 & 10 & 10 & 10 & 4 & 44 & $88 \%$ \\
\hline Total & 549 & 560 & 583 & 586 & 546 & & $\begin{array}{c}\text { Média da Pontuação } \\
\text { Possível }\end{array}$ \\
\hline \% da Pontuação possível & $78 \%$ & $80 \%$ & $83 \%$ & $84 \%$ & $78 \%$ & $\begin{array}{c}\text { Média da Pontuação } \\
\text { Possível }\end{array}$ & $81 \%$ \\
\hline
\end{tabular}

Fonte: Elaborado pela pesquisadora

Nas variáveis pesquisadas na dimensão acessibilidade atitudinal, todas alcançaram pontuação superior a $70 \%$, não tendo destaque para nenhuma delas. A diferença de percentual entre a de maior pontuação, AT4 (relacionamento com outros alunos), para as de menores percentuais, AT1 (recepção dos professores) e AT5 (relacionamento escola-família), ambas com $78 \%$ é de $6 \%$. 
Verifica-se que as escolas com menos de $50 \%$ de pontuação têm uma menor frequência. A maior pontuação atingida foi 50 ou $100 \%$ do total e deste dado fazem parte 19 escolas e a menor pontuação foi 0 ou $0 \%$ referente a 2 escolas.

Tabela 6 - Pontuações das escolas nas subdivisões das variáveis da Acessibilidade Programática 
CONHECIMENTO https://www.nucleodoconhecimento.com.br

\begin{tabular}{|c|c|c|c|c|c|c|c|c|}
\hline \multicolumn{10}{|c|}{ DIMENSÃO: ACESSIBILIDADE PROGRAMÁTICA } \\
\hline ESCOLAS & P1 & P2 & P3 & P4 & P5 & P6 & Pontos & $\begin{array}{c}\text { \% da Pontuação } \\
\text { possível }\end{array}$ \\
\hline 1. & 10 & 9 & 9 & 10 & 10 & 10 & 58 & $97 \%$ \\
\hline 2. & 10 & 10 & 10 & 10 & 10 & 10 & 60 & $100 \%$ \\
\hline 3. & 6 & 7 & 7 & 7 & 1 & 3 & 31 & $52 \%$ \\
\hline \multicolumn{7}{|c|}{ DIMENSÃO: ACESSIBILIDADE PROGRAMÁTICA } \\
\hline ESCOLAS & P1 & P2 & P3 & P4 & P5 & P6 & Pontos & $\begin{array}{c}\text { \% da Pontuação } \\
\text { possível }\end{array}$ \\
\hline 4. & 5 & 8 & 8 & 5 & 3 & 3 & 32 & $53 \%$ \\
\hline 5. & 8 & 6 & 6 & 6 & 8 & 1 & 35 & $58 \%$ \\
\hline 6. & 6 & 6 & 6 & 4 & 2 & 2 & 26 & $43 \%$ \\
\hline 7. & 9 & 9 & 9 & 9 & 1 & 1 & 38 & $63 \%$ \\
\hline 8. & 10 & 10 & 10 & 10 & 10 & 0 & 50 & $83 \%$ \\
\hline 9. & 5 & 5 & 7 & 6 & 6 & 6 & 35 & $58 \%$ \\
\hline 10. & 9 & 9 & 8 & 8 & 10 & 0 & 44 & $73 \%$ \\
\hline
\end{tabular}




\begin{tabular}{|c|c|c|c|c|c|c|c|c|}
\hline 11. & 7 & 6 & 6 & 2 & 2 & 2 & 25 & $42 \%$ \\
\hline 12 . & 0 & 0 & 0 & 0 & 0 & 0 & 0 & $0 \%$ \\
\hline 13. & 8 & 9 & 9 & 6 & 5 & 4 & 41 & $68 \%$ \\
\hline 14. & 5 & 5 & 10 & 10 & 9 & 9 & 48 & $80 \%$ \\
\hline 15. & 10 & 8 & 9 & 5 & 6 & 5 & 43 & $72 \%$ \\
\hline 16. & 9 & 6 & 6 & 4 & 8 & 6 & 39 & $65 \%$ \\
\hline 17. & 9 & 9 & 9 & 9 & 10 & 9 & 55 & $92 \%$ \\
\hline 18. & 8 & 2 & 2 & 1 & 1 & 3 & 17 & $28 \%$ \\
\hline 19. & 10 & 9 & 10 & 10 & 5 & 5 & 49 & $82 \%$ \\
\hline 20. & 6 & 8 & 8 & 4 & 5 & 2 & 33 & $55 \%$ \\
\hline 21. & 5 & 10 & 10 & 10 & 10 & 10 & 55 & $92 \%$ \\
\hline 22 . & 3 & 5 & 5 & 5 & 1 & 5 & 24 & $40 \%$ \\
\hline 23. & 6 & 6 & 6 & 1 & 6 & 1 & 26 & $43 \%$ \\
\hline 24. & 0 & 0 & 7 & 0 & 0 & 2 & 9 & $15 \%$ \\
\hline 25. & 10 & 10 & 10 & 10 & 10 & 5 & 55 & $92 \%$ \\
\hline 26. & 10 & 10 & 10 & 10 & 10 & 10 & 60 & $100 \%$ \\
\hline 27. & 8 & 8 & 8 & 6 & 6 & 0 & 36 & $60 \%$ \\
\hline 28. & 3 & 2 & 2 & 7 & 7 & 5 & 26 & $43 \%$ \\
\hline 29. & 7 & 7 & 7 & 7 & 7 & 7 & 42 & $70 \%$ \\
\hline 30. & 8 & 4 & 4 & 8 & 4 & 4 & 32 & $53 \%$ \\
\hline 31. & 7 & 4 & 4 & 3 & 4 & 1 & 23 & $38 \%$ \\
\hline 32. & 5 & 5 & 5 & 0 & 0 & 0 & 15 & $25 \%$ \\
\hline 33. & 4 & 4 & 5 & 0 & 0 & 0 & 13 & $22 \%$ \\
\hline 34. & 9 & 9 & 9 & 9 & 9 & 9 & 54 & $90 \%$ \\
\hline 35. & 5 & 5 & 5 & 8 & 8 & 5 & 36 & $60 \%$ \\
\hline 36. & 5 & 5 & 5 & 5 & 10 & 5 & 35 & $58 \%$ \\
\hline 37. & 8 & 8 & 8 & 9 & 10 & 7 & 50 & $83 \%$ \\
\hline 38. & 10 & 8 & 8 & 8 & 3 & 8 & 45 & $75 \%$ \\
\hline 39. & 5 & 5 & 5 & 5 & 10 & 5 & 35 & $58 \%$ \\
\hline 40 . & 10 & 10 & 10 & 8 & 8 & 0 & 46 & $77 \%$ \\
\hline 41. & 7 & 2 & 2 & 7 & 4 & 0 & 22 & $37 \%$ \\
\hline 42. & 10 & 3 & 7 & 2 & 1 & 3 & 26 & $43 \%$ \\
\hline 43. & 6 & 7 & 7 & 6 & 6 & 3 & 35 & $58 \%$ \\
\hline 44. & 9 & 10 & 10 & 9 & 10 & 9 & 57 & $95 \%$ \\
\hline 45. & 9 & 9 & 9 & 9 & 9 & 9 & 54 & $90 \%$ \\
\hline 46. & 10 & 10 & 6 & 3 & 8 & 10 & 47 & $78 \%$ \\
\hline 47. & 10 & 10 & 10 & 10 & 10 & 5 & 55 & $92 \%$ \\
\hline
\end{tabular}




\begin{tabular}{|c|c|c|c|c|c|c|c|c|}
\hline \multicolumn{8}{|c|}{ DIMENSÃO: ACESSIBILIDADE PROGRAMÁTICA } \\
\hline ESCOLAS & P1 & P2 & P3 & P4 & P5 & P6 & Pontos & $\begin{array}{c}\text { \% da Pontuação } \\
\text { possível }\end{array}$ \\
\hline 48. & 10 & 6 & 6 & 6 & 6 & 6 & 40 & $67 \%$ \\
\hline 49. & 4 & 6 & 6 & 4 & 5 & 2 & 27 & $45 \%$ \\
\hline 50. & 4 & 2 & 2 & 2 & 2 & 2 & 14 & $23 \%$ \\
\hline 51. & 9 & 9 & 9 & 8 & 8 & 8 & 51 & $85 \%$ \\
\hline 52. & 6 & 6 & 6 & 8 & 8 & 5 & 39 & $65 \%$ \\
\hline 53. & 10 & 10 & 10 & 9 & 9 & 7 & 55 & $92 \%$ \\
\hline 54. & 9 & 5 & 5 & 5 & 5 & 1 & 30 & $50 \%$ \\
\hline
\end{tabular}

\begin{tabular}{|c|c|c|c|c|c|c|c|c|}
\hline 55. & 5 & 1 & 3 & 0 & 0 & 0 & 9 & $15 \%$ \\
\hline 56. & 5 & 9 & 9 & 5 & 9 & 5 & 42 & $70 \%$ \\
\hline 57. & 5 & 0 & 0 & 5 & 5 & 5 & 20 & $33 \%$ \\
\hline 58. & 8 & 5 & 5 & 7 & 9 & 5 & 39 & $65 \%$ \\
\hline 59. & 10 & 9 & 9 & 5 & 9 & 2 & 44 & $73 \%$ \\
\hline 60. & 9 & 9 & 9 & 10 & 10 & 1 & 48 & $80 \%$ \\
\hline 61. & 10 & 5 & 5 & 5 & 5 & 10 & 40 & $67 \%$ \\
\hline 62. & 5 & 2 & 2 & 5 & 0 & 0 & 14 & $23 \%$ \\
\hline 63. & 5 & 3 & 3 & 5 & 2 & 3 & 21 & $35 \%$ \\
\hline 64. & 8 & 8 & 8 & 8 & 5 & 5 & 42 & $70 \%$ \\
\hline 65. & 10 & 10 & 10 & 10 & 10 & 10 & 60 & $100 \%$ \\
\hline 66. & 6 & 3 & 4 & 3 & 4 & 1 & 21 & $35 \%$ \\
\hline 67. & 9 & 8 & 8 & 10 & 0 & 5 & 40 & $67 \%$ \\
\hline 68. & 3 & 2 & 0 & 2 & 2 & 0 & 9 & $15 \%$ \\
\hline 69. & 9 & 5 & 8 & 8 & 10 & 0 & 40 & $67 \%$ \\
\hline 70. & 5 & 10 & 10 & 0 & 4 & 0 & 29 & $41 \%$ \\
\hline Total & 503 & 450 & 470 & 421 & 410 & 292 & & $\begin{array}{c}\text { Média da Pontuação } \\
\text { Possivel }\end{array}$ \\
\hline \% da Pontuação possível & $72 \%$ & $64 \%$ & $67 \%$ & $60 \%$ & $59 \%$ & $42 \%$ & $\begin{array}{l}\text { Média da Pontuação } \\
\text { Possível }\end{array}$ & $60 \%$ \\
\hline
\end{tabular}

Fonte: Elaborado pela pesquisadora

Nas 70 escolas pesquisadas verificaram-se 22 instituições, com uma pontuação abaixo da média simples de 30 pontos. Os dados da tabela 6 demonstram que 3 escolas produziram as maiores pontuações para a acessibilidade programática com totais de 60 pontos, a segunda maior pontuação foi de 58 pontos. A menor pontuação produzida foi 0 pontos.

A variável P1 (adequação do projeto político pedagógico) ficou com a maior pontuação obtendo 503 pontos. Com pontuação menor de 50\% ficou a variável P6 (sistema político eficaz). 
Paralelamente a aplicação do modelo de avaliação, as entrevistas com três gestores da Secretaria de Educação foram acontecendo. Os dados coletados no discursos dos entrevistados foram compilados na tabela 7 .

Tabela 7 - Compilação dos dados extraídos das entrevistas

\begin{tabular}{|c|c|c|c|}
\hline Tópicos & Gestor 1 & Gestor 2 & Gestor 3 \\
\hline $\begin{array}{l}\text { Formação } \\
\text { Acadêmica }\end{array}$ & 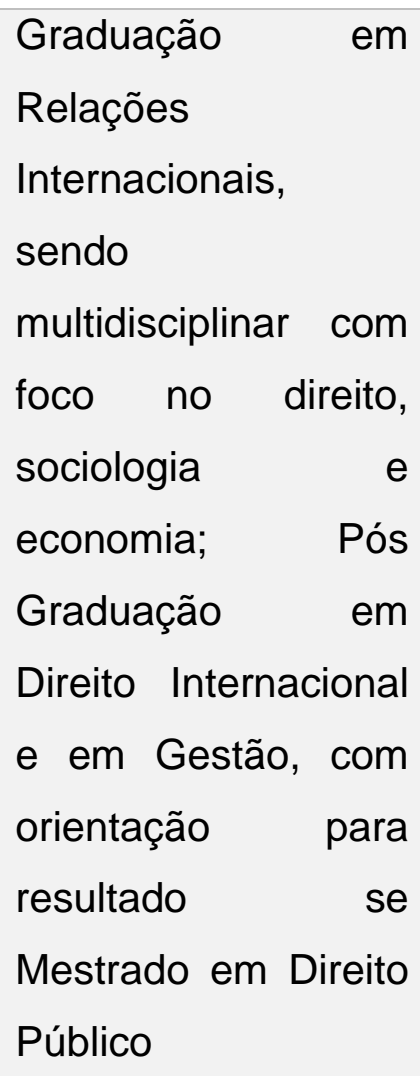 & $\begin{array}{lr}\text { Graduação em } \\
\text { Normal Superior, Pós } \\
\text { Graduação em } \\
\text { Psicopedagogia }\end{array}$ & $\begin{array}{l}\text { Graduação em } \\
\text { Psicologia, Pós } \\
\text { Graduação em } \\
\text { Educação Infantil } \\
\text { e Educação de } \\
\text { Jovens e Adultos; } \\
\text { Cursos de } \\
\text { Capacitação pelo } \\
\text { MEC, UFJF e } \\
\text { pelo país }\end{array}$ \\
\hline $\begin{array}{l}\text { Experiência } \\
\text { Profissional }\end{array}$ & $\begin{array}{lr}\text { Professor de ensino } \\
\text { superior, atuou em } \\
\text { diversos r } & \text { cargos } \\
\text { públicos } & \text { na } \\
\text { Prefeitura de } & \text { Belo } \\
\text { Horizonte, foi Diretor } \\
\text { da Companhia } \\
\text { URBEL e chefe } & \text { de } \\
\text { Gabinete } & \text { na } \\
\text { Secretaria } & \text { de }\end{array}$ & $\begin{array}{l}\text { Concursado como } \\
\text { Regente do Ensino } \\
\text { Fundamental, atuou } \\
\text { como professor } \\
\text { durante } 12 \text { anos, } \\
\text { passou por processo } \\
\text { eletivo e assumiu o } \\
\text { cargo de direção } \\
\text { escolar por } 6 \text { anos e } \\
\text { no ano de } 2013 \text { foi }\end{array}$ & $\begin{array}{l}\text { Concursado } \\
\text { como Psicólogo } \\
\text { Escolar, atuou } \\
\text { em escola de } \\
\text { educação infantil } \\
\text { particular, } \\
\text { assumiu cargo na } \\
\text { Secretaria de } \\
\text { Educação em } \\
1992 \text { e em } 1994\end{array}$ \\
\hline
\end{tabular}




\begin{tabular}{|c|c|c|c|}
\hline & $\begin{array}{l}\text { Governo e em } 2013 \\
\text { convidado a assumir } \\
\text { a Secretaria de } \\
\text { Educação de Juiz de } \\
\text { Fora passou a atuar } \\
\text { no cargo }\end{array}$ & $\begin{array}{l}\text { convidado a assumir a } \\
\text { chefia do } \\
\text { departamento de } \\
\text { ações pedagógicas }\end{array}$ & $\begin{array}{l}\text { assumiu o serviço } \\
\text { de educação } \\
\text { especial }\end{array}$ \\
\hline $\begin{array}{l}\text { Planejamento } \\
\text { da Educação } \\
\text { Inclusiva }\end{array}$ & 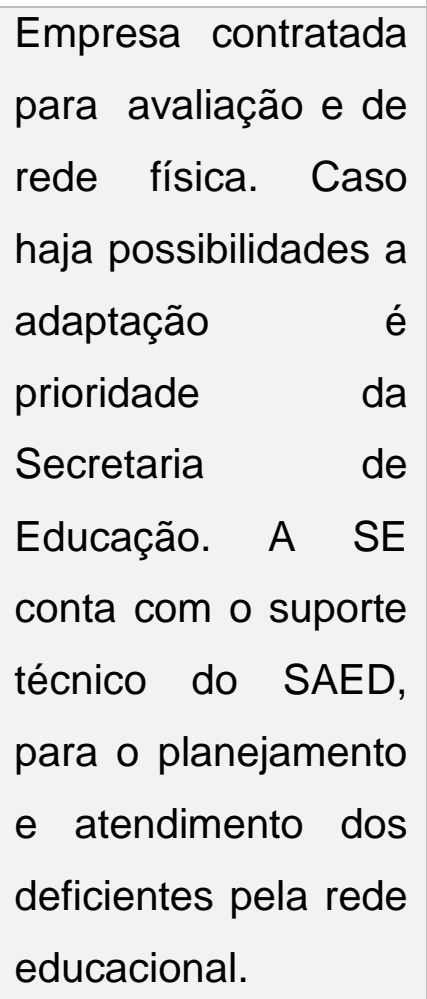 & $\begin{array}{l}\text { Trabalhando junto } \\
\text { com o SAED e a partir } \\
\text { de } 2014 \text { com o } \\
\text { Departamento de } \\
\text { Apoio ao Estudante - } \\
\text { DAE }\end{array}$ & $\begin{array}{l}\text { O planejamento } \\
\text { só envolve os } \\
\text { funcionários da } \\
\text { Secretaria de } \\
\text { Educação } \\
\text { trabalha-se na } \\
\text { perspectiva de } \\
\text { inclusão com as } \\
\text { crianças } \\
\text { estudando mais } \\
\text { próximas } \\
\text { possível de suas } \\
\text { casas }\end{array}$ \\
\hline $\begin{array}{l}\text { Avaliação da } \\
\text { Acessibilidade } \\
\text { nas Escolas } \\
\text { Atualmente }\end{array}$ & $\begin{array}{lr}\text { Analisou } & \text { a } \\
\text { acessibilidade a } & \text { partir da rede física. } \\
\text { Argumentou as } & \text { as } \\
\text { modificações para } \\
\text { promoção } \\
\text { acessibilidade física } \\
\text { não fácil, depende de } \\
\text { recursos financeiros } \\
\text { e possibilidades de } \\
\text { reestruturação para }\end{array}$ & $\begin{array}{l}\text { Relatou ter muito que } \\
\text { caminhar, as ações } \\
\text { ficam muito } \\
\text { esporádicas } \\
\text { dependente da } \\
\text { vontade dos diretores. } \\
\text { A Secretaria tem } \\
\text { como papel orientar e } \\
\text { levantar discussões. }\end{array}$ & 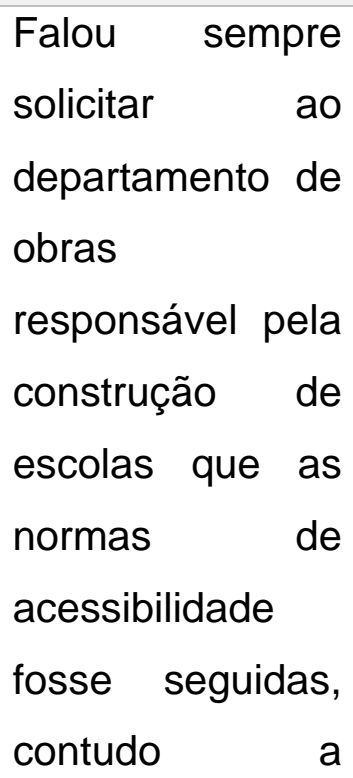 \\
\hline
\end{tabular}




\begin{tabular}{|c|c|c|c|}
\hline & $\begin{array}{l}\text { as adaptações, o que } \\
\text { as vezes é } \\
\text { impossível devido ao } \\
\text { espaço físico. }\end{array}$ & & $\begin{array}{l}\text { demanda da } \\
\text { sociedade a } \\
\text { opção muitas } \\
\text { vezes não é pela } \\
\text { acessibilidade }\end{array}$ \\
\hline $\begin{array}{l}\text { Planejamento } \\
\text { para } \\
\text { Implantação } \\
\text { e/ou Melhoria } \\
\text { da } \\
\text { Acessibilidade } \\
\text { Educacional }\end{array}$ & $\begin{array}{l}\text { Espera que com a } \\
\text { avaliação poder } \\
\text { atuar nos pontos } \\
\text { fracos na promoção } \\
\text { de acessibilidade e } \\
\text { aqueles locais que } \\
\text { tecnicamente não } \\
\text { poderá sofrer } \\
\text { alterações e é } \\
\text { preciso remanejar os } \\
\text { alunos para outros } \\
\text { ambientes } \\
\text { educacionais já } \\
\text { adaptados }\end{array}$ & $\begin{array}{l}\text { O DEAP trabalha em } \\
\text { conjunto com o SAED } \\
\text { no planejamento e a } \\
\text { partir das demandas } \\
\text { da escola vão } \\
\text { acontecendo as } \\
\text { ações }\end{array}$ & $\begin{array}{l}\text { A implantação de } \\
\text { acessibilidade } \\
\text { carece de } \\
\text { discussão, pois } \\
\text { ainda não são } \\
\text { todos que tem } \\
\text { esse } \\
\text { esclarecimento }\end{array}$ \\
\hline $\begin{array}{l}\text { Formação do } \\
\text { Professor }\end{array}$ & $\begin{array}{l}\text { Os grupos de } \\
\text { estudos e os cursos } \\
\text { existentes estão } \\
\text { sendo } \\
\text { potencializados e } \\
\text { criando novos cursos }\end{array}$ & $\begin{array}{l}\text { Continuidade da a } \\
\text { formação dos } \\
\text { bidocentes e cursos } \\
\text { elaborados através da } \\
\text { demanda }\end{array}$ & $\begin{array}{l}\text { A Secretaria de } \\
\text { Educação } \\
\text { disponibiliza } \\
\text { diversos cursos } \\
\text { gratuitos para } \\
\text { seus professores } \\
\text { e os grupos de } \\
\text { estudo para troca } \\
\text { de experiências }\end{array}$ \\
\hline $\begin{array}{l}\text { Dificuldades e } \\
\text { Facilidades na } \\
\text { Busca de uma }\end{array}$ & $\begin{array}{l}\text { Facilidade: grupo de } \\
\text { professores } \\
\text { profissionais do }\end{array}$ & $\begin{array}{lr}\text { Facilidade: } & \text { as } \\
\text { escolas } & \text { estarem } \\
\text { sempre de } & \text { portas }\end{array}$ & $\begin{array}{l}\text { Facilidade: } \\
\text { grande número } \\
\text { de professores }\end{array}$ \\
\hline
\end{tabular}




\begin{tabular}{|c|c|c|c|}
\hline $\begin{array}{l}\text { Educação } \\
\text { Inclusiva de } \\
\text { Qualidade } \quad \text { e } \\
\text { Eficiente }\end{array}$ & $\begin{array}{l}\text { magistério } \\
\text { aguerridos. } \\
\text { Dificuldade: } \\
\text { rede sem } \\
\text { planejamento e sem } \\
\text { foco no resultado, os } \\
\text { recursos precisam } \\
\text { ser otimizados }\end{array}$ & $\begin{array}{l}\text { abertas para o diálogo } \\
\text { e a vontade do } \\
\text { professor se capacitar } \\
\text { Dificuldade: } \\
\text { são os recursos e } \\
\text { infra estrutura }\end{array}$ & $\begin{array}{l}\text { Dificuldade: } \\
\text { mudança de } \\
\text { paradigma, de } \\
\text { concepção, de } \\
\text { pensamento, do } \\
\text { fazer e cotidiano }\end{array}$ \\
\hline
\end{tabular}

Fonte: Elaborado pela pesquisadora

É importante a comparação das formações e análise da equipe que gerencia a educação inclusiva no município de Juiz de Fora, pois as diferentes formações se configuram em elementos para fins de identificação de posturas profissionais. A visão "prática" desses entrevistados se consubstancia em sua formação e se tornam importante meio para fins de identificação dos ações no planejamento da educação inclusiva, bem como as diferenças entre as funções assumidas e as práticas destes.

As informações sobre as experiências profissionais dos gestores denotam que dois deles não tem experiência na vivência como educadores do ensino fundamental. Esse distanciamento da prática cotidiana do processo ensino aprendizagem poderá vir a influenciar decisões que afetaram a educação inclusiva, através políticas com bons discursos mas inviáveis na prática.

Com base no informado, o planejamento da educação inclusiva compete as decisões à uma equipe multidisciplinar, adotando-se a postura de compartilhamento de informações, trocas de experiências e respeito ao conhecimento técnico. Apesar do compartilhamento os três entrevistados demonstram insatisfação com o nível de acessibilidade atual das escolas municipais, enquanto rede é física, e não profissional e programática. Em nenhum momento das entrevistas outras acessibilidades foram relacionadas pelos entrevistados abrindo uma lacuna passível de conjunturas, não foi citado por desconhecimento ou por não ser foco de preocupações. Vale destacar que 
demonstram poucos conhecimentos de acessibilidades diversas. Fala-se novamente em planejamentos para o futuro ligadas as ações esporádicas, construção de acessibilidade arquitetônica, traçar estratégias e discussão sobre o tema. Porém planejamento concreto algum foi citado pelos entrevistados.

Tópico único de concordância entre os entrevistados, foi formação profissional sendo oferecidos cursos diversos de capacitação profissional para professor, ficando a cargo deste a inclusão. Formação para outros profissionais atuantes no âmbito escolar não foi mencionada.

As três falas pontuaram a postura do profissional como fator positivo, seja esta aguerrida, aberta ou política, não se traduz como obstáculos na implementação de acessibilidade, tornando-se ponto de unificação entre eles. De acordo com dois dos entrevistados, a questão financeira é a grande dificuldade, traduzida em entraves, a partir do momento que dificulta a construção de acessibilidade seja por falta de planejamento, seja por demanda de reestruturação física da rede municipal de educação.

\section{CONCLUSÃO}

Este estudo demonstrou que, na amostra pesquisada, há um grau maior de valoração de acessibilidade atitudinal, pois, entre as 70 escolas pesquisadas, 64 (que representa $91 \%$ do total) obtiveram notas superiores a 25 ou $50 \%$ de pontuação, sendo destacado também nesta dimensão atitudinal uma frequência de 100\% de pontuação por algumas escolas.

A promoção de acessibilidade arquitetônica na análise dos resultados da pesquisa, apesar de ser a dimensão primeira a aparecer na literatura pesquisada, é a que apesentou menor pontuação. Dentre as escolas pesquisadas 52 , ou seja $74 \%$ do total não alcançaram pontuação de 50\% e o maior índice alcançado na pontuação foi de $77 \%$. Outro destaque na dimensão arquitetônica foi o número de escolas com pontuação 0 no total de 110 pontos, foram ao todo 7 escolas, o que significa $10 \%$ total. 
Um percentual maior de escolas, com notas abaixo de 50\%, coube também á acessibilidade comunicacional, seguida, em ordem decrescente, da metodológica, programática, instrumental e atitudinal. Os dados indicam a possibilidade de uma certa relação de dependência entre a implementação das acessibilidades e os recursos financeiros, pois quanto maior a relação entre acessibilidade e a demanda financeira, menor é o percentual de notas das escolas. Em contraponto, os dados denotam a existência de fator de ligação entre acessibilidades e ações humanas, já que as escolas obtiveram notas maiores nas acessibilidades relacionadas as vontades dos indivíduos.

Os estudos realizados confirmam que as acessibilidades estudadas estão longe de compor um elo de ligação entre a inclusão e a qualidade da educação ligadas à pessoa com deficiência, tornando-as com isso um ponto de referência e de possibilidades de futuras intervenções. Através dos dados analisados dessa pesquisa conclui-se que a implantação de acessibilidades nas escolas do município de Juiz de Fora, apesar de já ter se iniciado ainda está distante da qualidade almejada.

\section{REFERENCIAS}

ABNT NBR9050: Acessibilidade a edificações, mobiliário, espaços e equipamentos urbanos. Associação Brasileira de Normas Técnicas, Rio de Janeiro; ABNT, 2004.

BRASIL. Decreto-lei no. 5.296, de 2 de dezembro de 2004. Regulamenta as Leis no 10.048 de 8 de novembro de 2000 e o 10.098 de 19 de dezembro de 2000 . . Instituto Brasileiro de Geografia e Estatística. IBGE. Censo 2010 . Lei №. 9394/96. Lei de Diretrizes e Bases da Educação Nacional. Brasília: Ministério da Educação, 1996. 
. Lei o 10.098, de 19 de dezembro de 2000. Estabelece normas gerais e critérios básicos para a promoção da acessibilidade das pessoas portadoras de deficiência ou com mobilidade reduzida, e dá outras providências.

. Ministério da Justiça. Coordenadoria Nacional para Integração da Pessoa Portadora de Deficiência. Declaração de Salamanca e linhas de ação sobre necessidades educativas especiais. Brasília: CORDE, 1994.

. Conselho Nacional de Educação. Resolução no 2, de 11 de setembro de 2001. Institui Diretrizes Nacionais para a Educação Especial na Educação Básica. Diário Oficial [da] República Federativa do Brasil, Poder Executivo, Brasília, DF, 14 set. 2001. Seção 1.

AUDI, E.M.M. e MANZINI, E.J. Avaliação da acessibilidade em escolas de ensino fundamental: descrição da metodologia para elaboração de protocolo. Arquitextos 081, Texto Especial 405, portal Vitruvius, 2007 Disponível em: <www.vitruvius.com.br/arquitextos/arq000/esp405.asp>. Acessado em: 06 jul. 2014.

Enviado: Agosto, 2020.

Aprovado: Novembro, 2020. 